Article

\title{
Enhanced Control Scheme for a Three-Phase Grid-Connected PV Inverter under Unbalanced Fault Conditions
}

\author{
Saeid Abbasi ${ }^{1}$, Ali Asghar Ghadimi ${ }^{1}{ }^{10}$, Amir Hossein Abolmasoumi ${ }^{1}$, \\ Mohammad Reza Miveh ${ }^{2}$ and Francisco Jurado ${ }^{3, * \mathbb{D}}$ \\ 1 Department of Electrical Engineering, Faculty of Engineering, Arak University, Arak 38156-8-8349, Iran; \\ Saeidabasi88@gmail.com (S.A.); a-ghadimi@araku.ac.ir (A.A.G.); a-abolmasoumi@araku.ac.ir (A.H.A.) \\ 2 Department of Electrical Engineering, Tafresh University, Tafresh 39518-79611, Iran; miveh@tafreshu.ac.ir \\ 3 Department of Electrical Engineering, University of Jaen, 23700 Linares, Spain \\ * Correspondence: fjurado@ujaen.es
}

Received: 29 June 2020; Accepted: 27 July 2020; Published: 3 August 2020

\begin{abstract}
This paper presents an improved control strategy to cancel the double grid frequency oscillations in the active power, reactive power, and DC-link voltage of a three-phase grid-connected photovoltaic (PV) system under unbalanced grid condition. To achieve these goals, an enhanced positive-negative-sequence control (PNSC) to remove oscillations of active power and an instantaneous active-reactive control (IARC) to mitigate the fluctuations of active and reactive power, simultaneously, are suggested. These methods are also effective to reduce the oscillations of the DC-link voltage. To track the desired unbalanced or harmonic reference currents, improved proportional resonant (PR) current controllers have been designed using the Bode frequency analysis. Simulation studies are carried out via Matlab/Simulink ${ }^{\circledR}$ software to verify the effectiveness of the suggested control strategies.
\end{abstract}

Keywords: current control; frequency locked-loop; power control; power oscillation; unbalanced grid voltage

\section{Introduction}

Despite numerous benefits provided by large power plants, economic, technical, and environmental advantages have led to the gradual development of small-scale renewable energy resources (RERs) into the power system [1-5]. Among different types of RERs, solar photovoltaic (PV) is a suitable choice owing to the possibility of direct conversion of sunlight into electricity using power electronic devices [6,7]. This system can operate in two main operation modes, including grid-connected and stand-alone [8]. However, to achieve a reliable operation during normal and grid fault conditions, some regulatory and technical problems such as constraints set by power generation systems have to be resolved before PV systems can become commonplace.

In recent years, there has been increasing interest in power quality in grid-connected PV inverters under grid faults, as the non-sinusoidal current is injected into the power system under such conditions, and the active/reactive power includes double frequency contents [9]. These oscillations in the active/reactive power can lead to undesired variation in the DC-link voltage. Fundamentally, oscillations occur due to the poor performance of both current control strategies of the PV system and the grid synchronization system.

Based on the recently revised grid codes, PV inverters are preferred to stay connected to the power system during grid voltage faults and contribute to the grid stability and power quality by 
providing ancillary services. This capability is low-voltage ride-through. Basically, the low-voltage ride-through control technique for three-phase grid-connected PV inverters during unbalanced grid faults is responsible for detecting voltage faults rapidly, calculating active/reactive current references in the positive and negative sequences, preventing overcurrent failure and controlling the DC-link voltage.

Different control approaches for low-voltage ride-through improvement in PV systems during grid fault conditions have been presented in the literature. The low-voltage ride-through capability of a single-phase grid-connected PV system is investigated in [10]. A review of the existing current reference calculation methods is provided in [11]. To inject power into the utility grid, a proportional-integral (PI) controller in the synchronous frame is used in [12]. This method has computational complexity, as it requires specific filters and separate sequences. The proportional resonant (PR) current controller in the stationary reference frame is proposed for a three-phase PV system in [13], which its implementation is simpler than the PI controller. In [14,15], the performance of the PR and PI current controllers and their transient response are compared. However, this study has not been resolved the problem of the distorted response of the phase-locked loop (PLL) under grid fault conditions. In [16], an active filter with the PR controller for controlling the current of a voltage source converter (VSC) in a balanced harmonic voltage condition is recommended and the PLL performance is improved.

In [17], a mathematical control model for the VSC in the synchronous reference frame with the PR compensator has been proposed under abnormal conditions. Nevertheless, the performance of the three-phase PV system connected to the grid and the requirement of the accurate synchronization system are not investigated. Moreover, the generation of proper reference current controller during grid fault conditions is not surveyed. In [18], power control methods are studied, but their implementation and performance in the PV system are not represented. New control approaches for a three-level PV inverter to further balance the voltage fluctuations on the neutral point under unbalanced faults are proposed in [19]. The low-voltage ride-through capability of current source PV inverters are also investigated in [20]. A flexible control approach for the operation of three-phase PV inverters under unbalanced faults is suggested in [21]. Nonetheless, in this paper the control of the renewable energy source is not discussed.

This paper introduces a flexible reference current generator to overcome the power oscillations under unbalanced grid faults. The suggested control technique can eliminate double grid frequency oscillations injected from the active/reactive power and the DC link voltage under unbalanced grid voltage conditions. Moreover, a non-ideal PR controller with harmonic compensators is proposed to track the generated reference current. An effective approach is also used to extract suitable controller parameters with an analytical method.

The rest of the paper is organized as follows: The foundation of the PV system modeling for unbalanced grid conditions is given in Section 2, including the three main subsections: the synchronization system, the maximum power-point tracking (MPPT) algorithm, and the PR current controller. The proposed power control method to improve the PV inverter performance is presented in Section 3. The verification of the model is presented in Section 4 and, finally, Section 5 concludes the paper.

\section{PV System Modeling}

The single-line block diagram of a three-phase grid-connected PV system is shown in Figure 1. As seen, the system consists of a VSC and a DC-DC converter, which brings the advantage of independent operation of power controller and the MPPT control, respectively [22]. The state-space equations of the system are given in $[23,24]$. Moreover, the small-signal analysis is investigated in the $\mathrm{dq}$ frame [18]. The design of the LCL filter and capacitor C are based on [18]. 


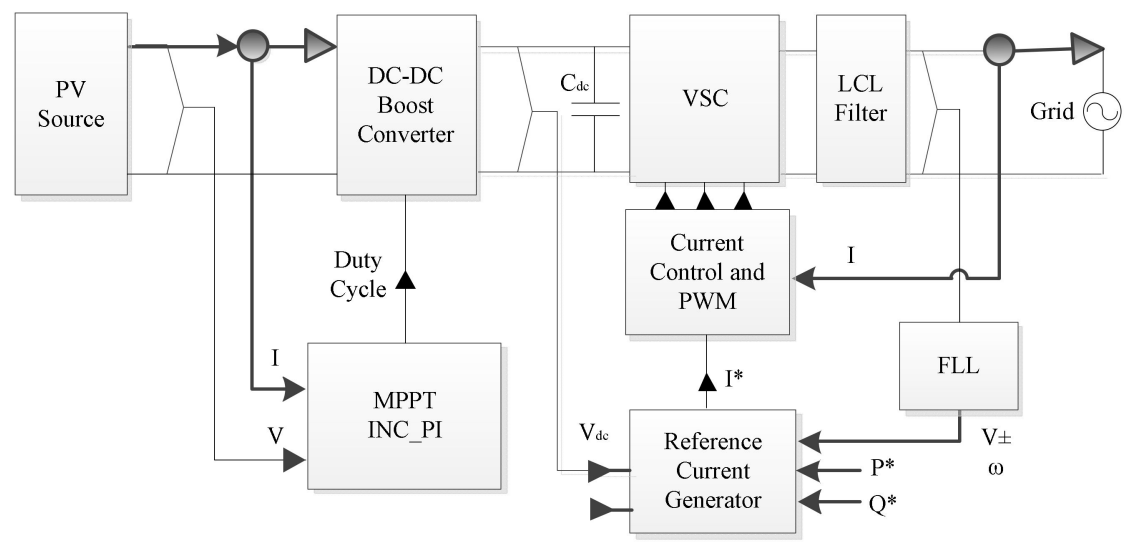

Figure 1. Block diagram of the grid-connected photovoltaic (PV) system.

All required properties for the PV system are presented in the following: (1) maximum utilization of PV panels in working hours; this is mainly attributed under any environmental conditions; (2) regulating the DC-link voltage to guarantee the proper performance of the inverter, applying via changes in duty cycle; (3) injecting smooth power by the inverter to ensure the power quality requirement of the utility grid; and (4) providing precise phase information of the grid positive-sequence voltage for the control unit by a fast and precise synchronization system.

In the DC-DC converter, the required control signal (duty cycle) is determined by the MPPT algorithm. In addition, there are two control loops in the power control of a VSC: (1) an outer control loop is responsible for generating the reference current to regulate the DC-link voltage and injecting the desired power to the network and (2) an inner control loop with the task of tracking the reference current generated by the outer control loop. In this system, a frequency-locked loop (FLL) control block synchronizes the PV inverter with the power grid and provides a specific phase angle.

\subsection{FLL Synchronization System}

Under normal conditions, the synchronous reference frame PLL (SRF-PLL) is an effective synchronization method. However, under unbalanced voltage conditions, the system provides distorted phase information due to operating based on a fixed phase difference. To solve this problem, an FLL synchronization system is suggested in $[18,25,26]$. FLLs operate based on the grid frequency, which its change is much slower than the grid voltage phase-angle. It estimates the grid angle from positive- and negative-sequence components of the voltage signal at the fundamental frequency. FLL is able to achieve frequency adaptability by a simple control loop, without using either phase-angles or trigonometric functions. Hence, it acts as an adaptive filter to frequency changes that may occur in the grid system $[25,27,28]$. In this paper, a double second-order generalized integrator FLL (DSOGI-FLL) is used for phase detection, and it is adapted to the DC-DC/VSC control structure. The structure of the DSOGI-FLL is shown in Figure 2, which is composed of two active filters second-order generalized integrator-quadrature signal generator (SOGI-QSG) blocks, positive-negative-sequence calculation (PNSC) block and the FLL $[27,29,30]$. The SOGI-QSG blocks are active filters and can convert input sinusoidal signal to square output signal. These blocks are also effective in eliminating high-order harmonics. The calculator block of the PNSC operates with the method of sequence components in the $\alpha \beta$ reference frame. 


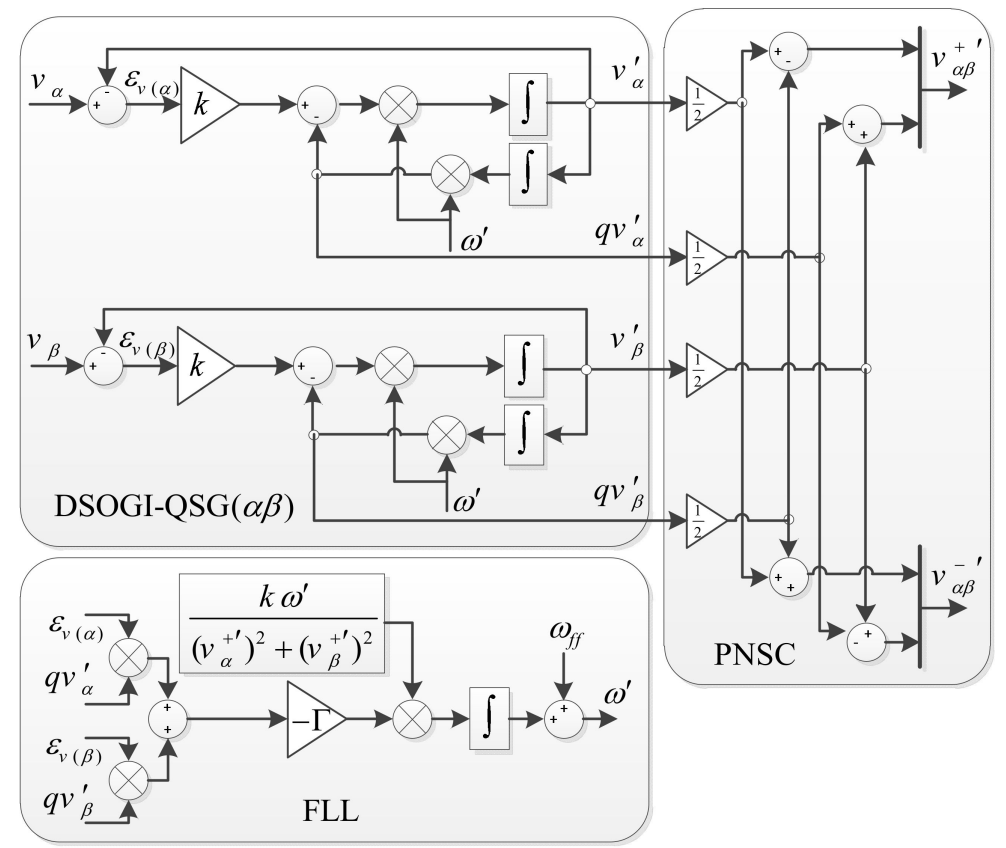

Figure 2. Block diagram of the double second-order generalized integrator frequency-locked loop (DSOGI-FLL) divided into its building blocks: second-order generalized integrator-quadrature signal generator (SOGI-QSG) ( $\beta$ ), SOGI-QSG $(\alpha)$, FLL and positive-negative-sequence calculation (PNSC).

\subsection{MPPT Method}

The energy conversion efficiency in PV systems is mainly related to the output current of the converter and atmospheric conditions. To take into account all the effective factors to improve the efficiency, MPPT algorithms are proposed in [31]. In [32,33], several methods with different implementations, from primary to advanced procedures are introduced. Incremental conductance (INC) method with the PI controller is one of the best solutions. Figure 3 indicates the INC-MPPT block diagram with the PI feedback, which is used as the MPPT method in this paper. The INC method is based on the fact that the power slope of the PV is null at the MPP $(\mathrm{dP} / \mathrm{dV}=0)$, positive in the left and negative on the right side of the PV power characteristic. Thus, the MPP can be found in terms of the increment in the array conductance. This method also features a modified version and does not suffer from fast transients in environmental conditions. The PI controller improves the IC method by minimizing the error between the actual conductance and the incremental conductance because the compensator can be adjusted and updated according to the system necessity.

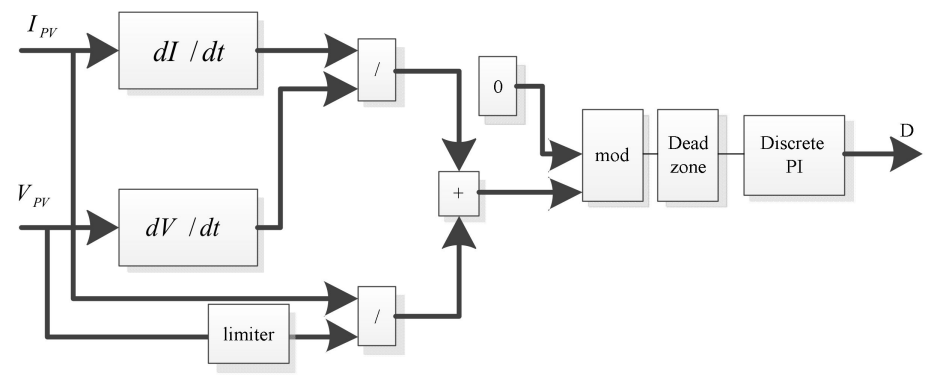

Figure 3. Incremental conductance (INC) method with the proportional-integral (PI) controlling feedback.

\subsection{Current Controller}

To generate appropriate pulse-width modulation (PWM) signals that are applied to inverter switches, conventional PI controllers use the difference between dq components of VSC currents 
and the reference currents. In normal situations, the reference current is constant (in both the d and $\mathrm{q}$ axis). However, it is no longer a fixed value under unbalanced grid voltage conditions. In other words, the reference currents have a sinusoidal form by twice of fundamental grid frequency due to cross-coupling between the dq axis signals and contain positive and negative sequences, which cannot generally be tracked by a PI controller [29]. In control systems theory, to track sinusoidal signals, PR controllers are usually utilized [34]. The PR controller solves this problem by using the grid frequency, which is the same for either of the two sequences' components. A single PR control with the ability to track the sinusoidal signal is enough to compensate the positive and negative sequences, simultaneously. Three main types of PR controllers are introduced in the following section: (I) ideal PR controller, (II) non-ideal PR controller, and (III) non-ideal PR controller with harmonic compensators.

\subsubsection{Type I: Ideal PR Controller}

The transfer function of the ideal PR controller is [35]:

$$
G_{P R}=k_{p}+\frac{k_{i} s}{s^{2}+\omega^{2}}
$$

where, $\omega$ is grid frequency in $(\mathrm{rad} / \mathrm{sec})$ and $k_{p}$ and $k_{i}$ are the proportional and integral gains.

This controller has an infinite gain at the grid frequency with a slight bandwidth to obtain a zero steady-state error in the tracking of the sinusoidal signal at the grid frequency based on Equation (1) and Bode diagram of Figure 4 [16]. The block diagram of the ideal PR current controller is also shown in Figure 5. The narrow bandwidth can cause the performance of the controller so sensitive to the central frequency value; hence, the non-ideal PR controller is preferred in practice.

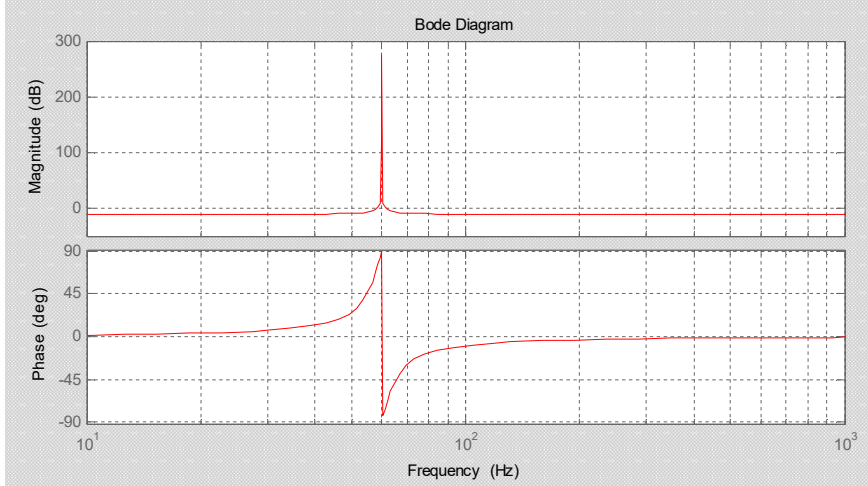

Figure 4. Bode diagram of the ideal proportional resonant (PR) controller.

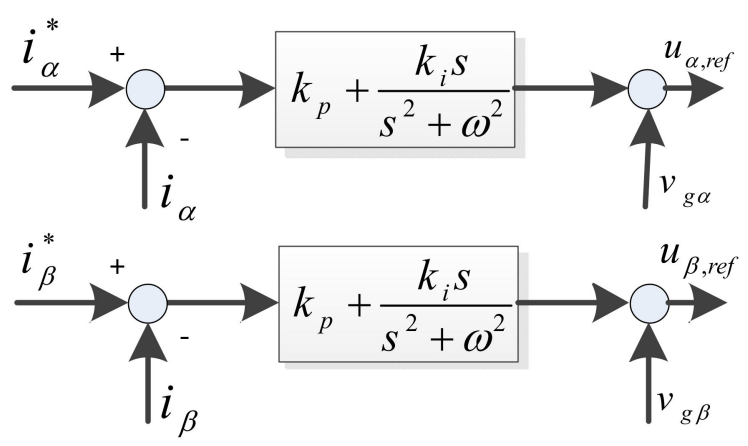

Figure 5. Standard ideal PR controller in the stationary reference frame. 


\subsubsection{Type II: Non-Ideal PR Controller}

The transfer function of the non-ideal PR controller is:

$$
\begin{gathered}
G_{P R}=k_{p}+\frac{k_{i} B W s}{s^{2}+B W s+\omega^{2}} \\
B W=2 \xi \omega
\end{gathered}
$$

In Equation (2), the bandwidth of the controller can be adjusted by $B W$, which is determined by damping factor $\xi$. This means that by increasing $\xi$, the bandwidth would be wider. The Bode diagram of the non-ideal PR is shown in Figure 6. As can be seen, the bandwidth is wider when compared with the ideal PR controller. The block diagram of the non-ideal PR controller is displayed in Figure 7.

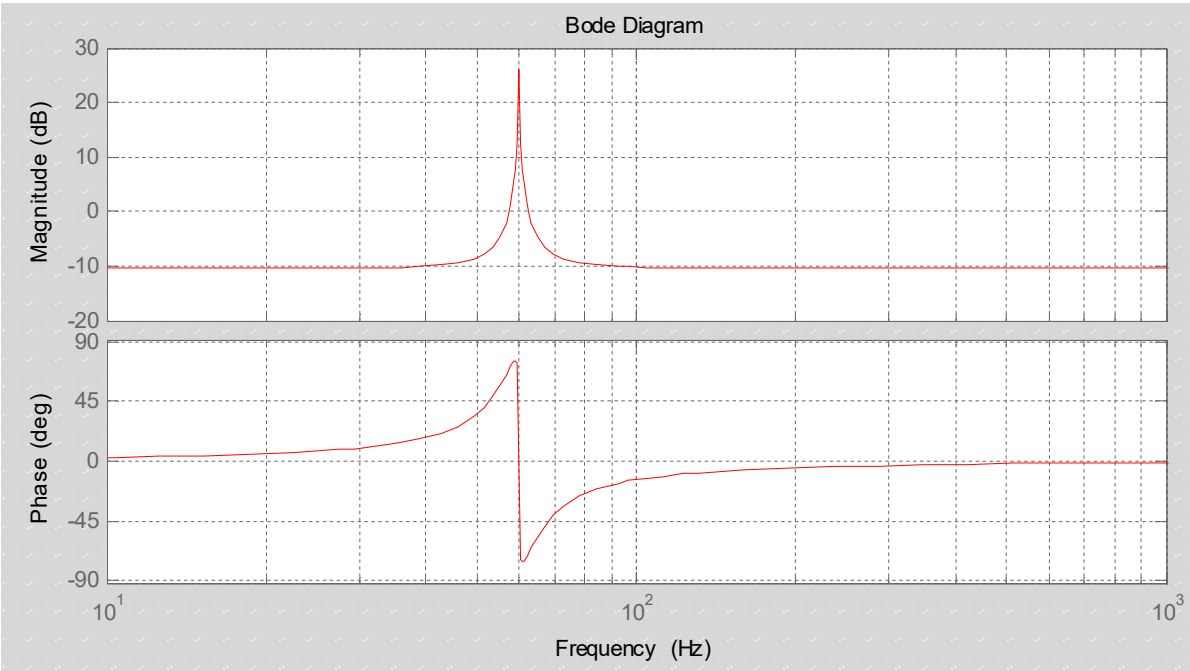

Figure 6. Bode diagram of the non-ideal PR controller.

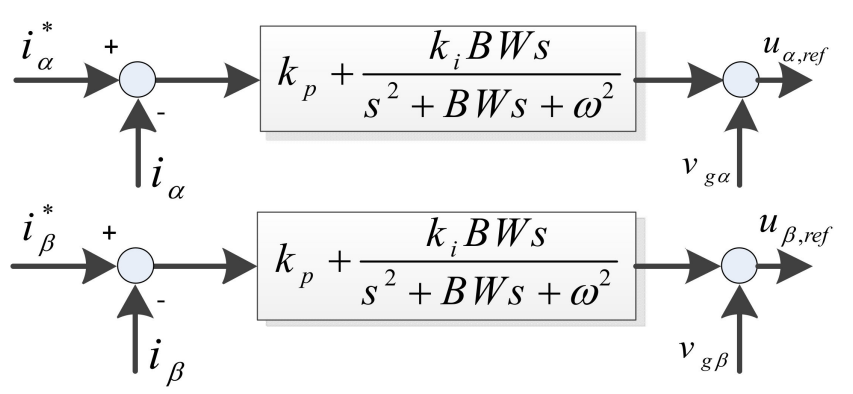

Figure 7. Standard non-ideal PR controller in the stationary reference frame.

Henceforth, under normal grid conditions, the non-ideal PR current control will be able to track sinusoidal signals. However, it is not responsible to track the reference three-phase sinusoidal signals, which present harmonics in their waveform. Tracking these signals is essential for controlling active and reactive power, simultaneously [18]. Hence, the PR controller with a harmonic compensator will be applied in this paper.

\subsubsection{Type III: Non-Ideal PR Controller with a Harmonic Compensators}

The standard PR controller is made by using the PR controller for each phase. In the last implementation, several resonant compensators tuned at the fundamental and other harmonic frequencies are connected in parallel. In this case, the reference sinusoidal signal, which contains 
harmonics can be correctly tracked. The transfer function of the non-ideal PR controller with harmonic compensators is written as follows:

$$
G_{P R-H}=k_{p}+\frac{k_{i} B W s}{s^{2}+B W s+\omega^{2}}+\frac{k_{i 3} B W_{3} s}{s^{2}+B W_{3} s+(3 \omega)^{2}}+\frac{k_{i 5} B W_{5} s}{s^{2}+B W_{5} s+(5 \omega)^{2}}+\frac{k_{i 7} B W_{7} s}{s^{2}+B W_{7} s+(7 \omega)^{2}}
$$

The open-loop gain Bode diagram of the non-ideal PR controller, with and without the third, fifth, and seventh harmonic compensators, is presented in Figure 8. The open-loop crossover frequency of the controller must be higher than the highest harmonic frequency to ensure the tracking performance of the closed-loop system. The crossover frequency is adjusted by $k_{p}$ and will be limited by the stability of the gain margin [36]. Added harmonic compensators have no significant impact on the desired property of the primary PR controller; enabling the tracking of the main frequency [18]. Furthermore, this controller is capable of compensating both positive and negative sequences. The block diagram of this controller is shown in Figure 9.

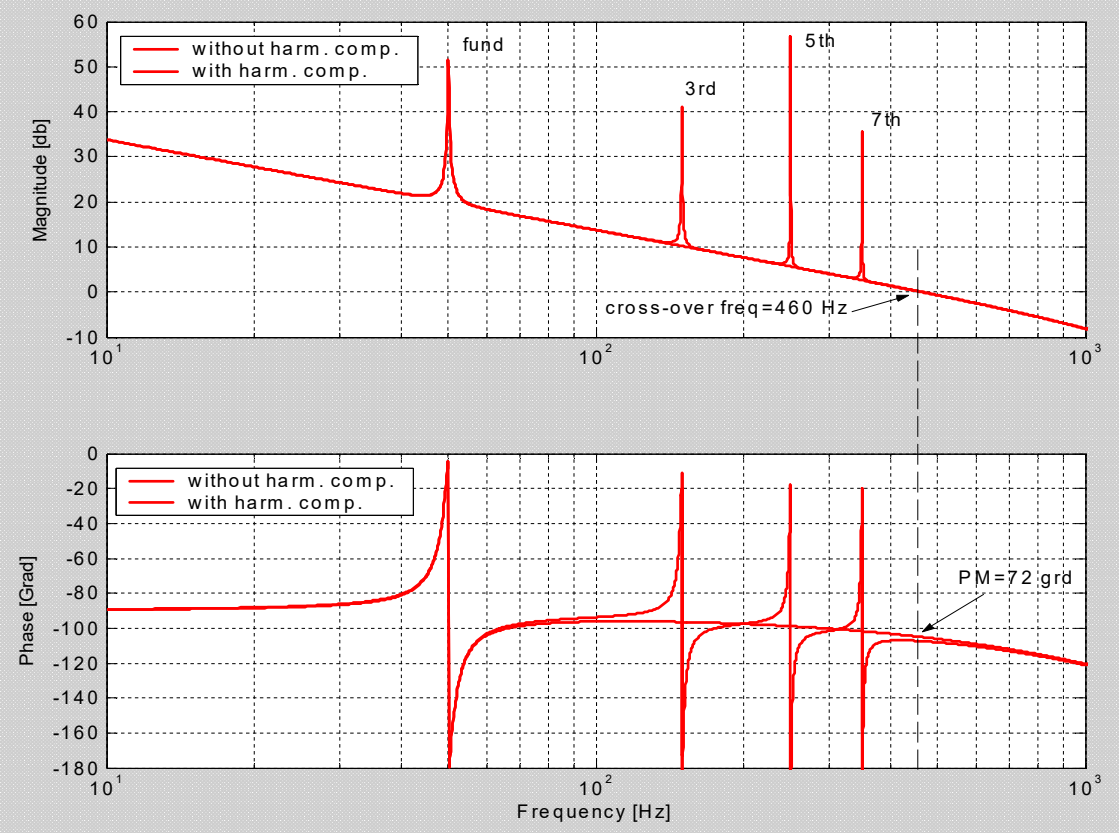

Figure 8. Bode diagram of the open-loop gain using the PR current control system with and without harmonic compensators.

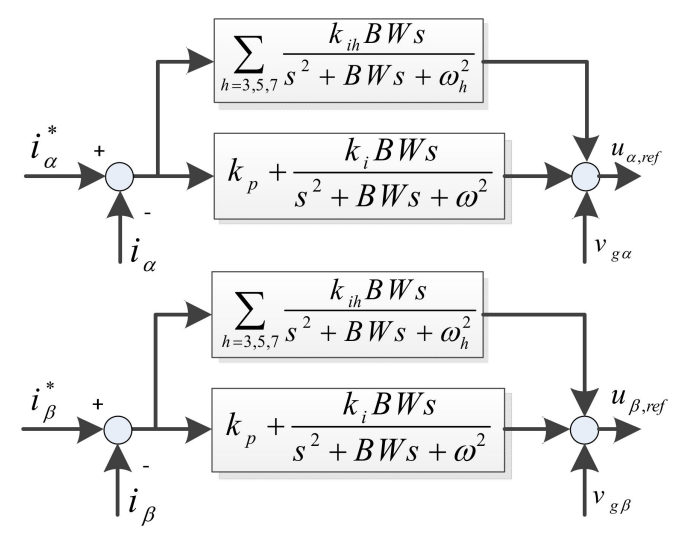

Figure 9. Standard non-ideal PR controller with harmonic compensators in the stationary reference frame. 
In designing the PR current controller, the elements of two sequences of grid voltage in the frequency domain can be expressed as follows:

$$
\begin{gathered}
v(s)_{\alpha \beta}=v(s)_{\alpha \beta^{+}}+v(s)_{\alpha \beta^{-}} \\
{\left[\begin{array}{c}
v(s)_{\alpha} \\
v(s)_{\beta}
\end{array}\right]=\left[\begin{array}{cc}
k_{p}+\frac{k_{i} B W s}{s^{2}+B W s+\omega^{2}} & 0 \\
0 & k_{p}+\frac{k_{i} B W s}{s^{2}+B W s+\omega^{2}}
\end{array}\right]\left[\begin{array}{c}
\Delta i_{\alpha} \\
\Delta i_{\beta}
\end{array}\right]}
\end{gathered}
$$

Based on Equation (5) $v(s)_{\alpha \beta}$ contains both sequence components of grid voltage. Additionally, Equation (6) shows the relationship between voltage and current elements. The diagonal matrix form in Equation (6) indicates no cross-coupling between phases. Thus, based on Equations (5) and (6), a PR controller with the ability of tracking the sinusoidal signal on the stationary reference frame is able to cancel out the error on the positive and negative sequence components in an unbalanced situation.

\section{Proposed Power Control Method}

Under abnormal conditions, the instantaneous control of active and reactive power exchanged with the utility grid is highly important. Due to the interaction between voltages and currents with different sequences at the point of common coupling (PCC), the exchanged power will be oscillating. In this regard, the first step is the calculation of instantaneous active and reactive powers.

Basically, the orthogonal voltage $\left(v_{\perp}\right)$ in Equation (7) is $90^{\circ}$ leaded of the original grid voltage vector $(v)$. Considering Equation (7), the instantaneous active and reactive power would be calculated in the time domain as Equations (7) and (8), respectively. More details about transformation into the stationary frame and dq reference frame are given in [18].

$$
\begin{gathered}
v_{\perp \alpha \beta}=\left[\begin{array}{cc}
0 & -1 \\
1 & 0
\end{array}\right] v_{\alpha \beta} \\
p=V \cdot I=v^{+} \cdot i^{+}+v^{-} \cdot i^{-}+v^{+} \cdot i^{-}+v^{-} \cdot i^{+}=\bar{p}+\widetilde{p} \\
q=|V \cdot I|=v_{\perp}{ }^{+} \cdot i^{+}+v_{\perp}{ }^{-} \cdot i^{-}+v_{\perp}{ }^{+} \cdot i^{-}+v_{\perp}{ }^{-} \cdot i^{+}=\bar{q}+\widetilde{q}
\end{gathered}
$$

where, $\bar{p}, \bar{q}$ are constant terms of exchanged power and $\tilde{p}, \widetilde{q}$ are the oscillating terms.

Under abnormal conditions, two issues are important for PV systems; power oscillation terms and current harmonics [25]. In the following, the PNSC and the instantaneous active-reactive control (IARC) are proposed. The PNSC method has the capability to cancel out the active power oscillations without injecting the current harmonics. This method can be implemented on active load systems that no need to inject reactive power. For instance, if the injection of active power into the network is considered, while the reactive power set-point is equal to zero, the active power oscillations are mitigated. Thus it can be more beneficial economically than the IARC method. On the other hand, the IARC method has the ability to remove both active and reactive power oscillations simultaneously along with the current harmonics.

\subsection{PNSC}

As the proposed controller is for a three-leg inverter operating in a three-phase three-wire system, the control of the quantities of the zero-sequence is not included in the design of the control system. To determine the expressions for the reference currents generated by the PNSC strategy, it is initially assumed that only active power is delivered to the grid. In order to calculate the considered reference currents, injected currents and power terms are as follows:

$$
\begin{gathered}
i^{*}=i^{*+}+i^{*-} \\
\bar{p}=v^{+} \cdot i_{p}^{*+}+v^{-} \cdot i_{p}^{*-}
\end{gathered}
$$




$$
\widetilde{p}=v^{+} \cdot i_{p}^{*-}+v^{-} \cdot i_{p}^{*+}=0
$$

In regards to Equation (12):

$$
i_{p}^{*-}=-\frac{v^{+} \cdot i_{p}^{*+}}{\left|v^{+}\right|^{2}} v^{-}
$$

By substituting Equation (13) in Equation (11):

$$
i_{p}^{*+}=\frac{\bar{p}}{\left|v^{+}\right|^{2}-\left|v^{-}\right|^{2}} v^{+}
$$

Hence, by mixing Equations (10), (13), and (14):

$$
i_{p}^{*}=\frac{\bar{p}}{\left|v^{+}\right|^{2}-\left|v^{-}\right|^{2}}\left(v^{+}-v^{-}\right)
$$

Now with previous assumptions on the reactive power, $i_{q}^{*}$ can be written as:

$$
i_{q}^{*}=\frac{\bar{Q}}{\left|v^{+}\right|^{2}-\left|v^{-}\right|^{2}}\left(v_{\perp}{ }^{+}-v_{\perp}{ }^{-}\right)|v|^{2}=v_{a}^{2}+v_{b}^{2}+v_{c}^{2}=v_{\alpha}^{2}+v_{\beta}^{2}=v_{d}^{2}+v_{q}^{2}
$$

where $|v|^{2}$ is the norm of the grid voltage vector signal that is proposed for different reference frames as follows:

$$
|v|^{2}=v_{a}^{2}+v_{b}^{2}+v_{c}^{2}=v_{\alpha}^{2}+v_{\beta}^{2}=v_{d}^{2}+v_{q}^{2}
$$

Equation (17) represents that the proposed method can be implemented in different reference frames with different controllers. Thus, reference current can be given as:

$$
i^{*}=i_{p}^{*}+i_{q}^{*}
$$

Therefore, the active and reactive powers can be given as:

$$
\begin{aligned}
& p=v^{+} \cdot i_{p}^{+}+v^{-} \cdot i_{p}^{-}+v^{+} \cdot i_{q}^{+}+v^{-} \cdot i_{q}^{-}+v^{+} \cdot i_{p}^{-}+v^{-} \cdot i_{p}^{+}+v^{+} \cdot i_{q}^{-}+v^{-} \cdot i_{q}^{+} \\
& q=v_{\perp}^{+} \cdot i_{q}^{+}+v_{\perp}^{-} \cdot i_{q}^{-}+v_{\perp}^{+} \cdot i_{p}^{+}+v_{\perp}^{-} \cdot i_{p}^{-}+v_{\perp}^{+} \cdot i_{q}^{-}+v_{\perp}^{-} \cdot i_{q}^{+}+v_{\perp}^{+} \cdot i_{p}^{-}+v_{\perp}^{-} \cdot i_{p}^{+}
\end{aligned}
$$

The third and fourth terms are mitigated in both the above equations, as the dot product between two components with the same sequence and $90^{\circ}$ shifted is equal to zero. On the other hand, the fifth and the sixth terms are zero due to the conditions stated in Equation (12), and the first assumption, where both oscillating terms forced to be zero when calculating the reference for the active and reactive currents.

In the PSNC method, fluctuations in the active power can be mitigated completely, and the injected current would be sinusoidal without any harmonics. Therefore, the non-ideal PR compensator is proper to track the reference currents in the PSNC technique. The inner and outer loop of the current controller using the PNSC method, along with the DSOGI-FLL is shown in Figure 10. 


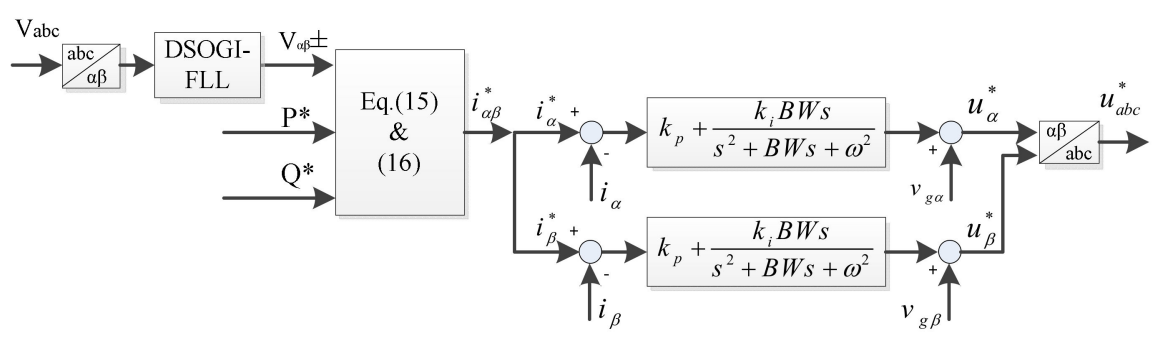

Figure 10. The inverter current control loop by implementing the PNSC method.

\subsection{IARC}

Under unbalanced grid voltage conditions, the voltage vector oscillates at twice the fundamental grid frequency, as Equation (21) [18].

$$
\left|v_{i}\right|^{2}=\left|v_{i}{ }^{+}\right|^{2}+\left|v_{i}^{-}\right|^{2}+2\left|v_{i}{ }^{+}\right|\left|v_{i}{ }^{-}\right| \cos \left(2 \omega t+\varphi^{+}-\varphi^{-}\right) i=a, b, c
$$

To provide smooth active and reactive powers, simultaneously, reference currents are calculated as follows:

$$
\begin{aligned}
& g=\frac{P^{*}}{\sum_{i=a, b, c}\left|v_{i}\right|^{2}} \\
& b=\frac{Q^{*}}{\sum_{i=a, b, c}\left|v_{i}\right|^{2}}
\end{aligned}
$$

In Equations (22) and (23) the active and reactive reference power can be calculated as Equations (8) and (9), which oscillating terms have been set to zero, and constant terms are obtained based on the output power. Where $g$ and $b$ represent instantaneous conductance and susceptance, from the inverter output, respectively. $i_{p}^{*}$ and $i_{q}^{*}$ are proper reference currents as follows:

$$
\begin{aligned}
& i_{p}^{*}=g\left(\sum_{i=a, b, c}\left(v_{i}^{+}+v_{i}^{-}\right)\right) \\
& i_{q}^{*}=b\left(\sum_{i=a, b, c}\left(v_{i_{\perp}}^{+}+v_{i_{\perp}}^{-}\right)\right)
\end{aligned}
$$

Thus, the reference currents are determined as:

$$
i^{*}=i_{p}^{*}+i_{q}^{*}
$$

These currents are the most efficient reference currents that determine the exact reference currents to exchange constant power with the main grid, under generic voltage conditions. Hence, these currents have the highest degree of control. Although the generated reference currents lead to smooth output active and reactive power, they include harmonic terms. This is because when the expression of Equation (21) is processed in the denominator, the resulting reference currents are not sinusoidal, but contain harmonics. Therefore, a non-ideal PR controller with harmonic compensation property has to be utilized here to achieve the proper tracking performance. In addition, the instantaneous control of the active and reactive power means the instantaneous tracking of the sinusoidal waveform of an unbalanced harmonic current in the controller. The current control loop to implement this method is shown in Figure 11. 


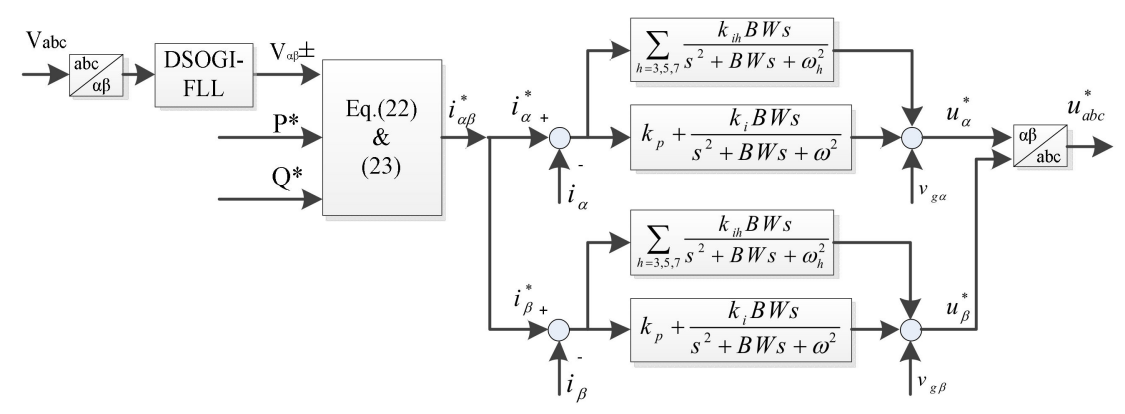

Figure 11. The inverter current control loop by implementing the instantaneous active-reactive control (IARC) method.

\subsection{Controller Design Using Bode Frequency Analysis}

The PR controller contains the term of proportional $k_{p}$ and integral $k_{i}$ gains. In order to fulfill a damping factor of 0.7 and overshoot less than $5 \%$, the modulus criterions can be calculated as $[25,37]$ :

$$
\begin{aligned}
& k_{p_{c r t}}=\frac{L}{2 T_{\sum 1}}=0.34 \\
& k_{\text {icrt }}=\frac{R k_{p c r t}}{L}=3.44
\end{aligned}
$$

where $L$ is the summation of series inductance and $R$ is the summation of series resistance of interfaced LCL filter and $T_{\Sigma 1}=1.5 T_{s}+0.5 T_{s w}$ and $T_{s}=\frac{1}{f_{s}}$ and $T_{s w}=\frac{1}{f_{s w}}$. The closed-loop control system must be considered to attain the proper value of parameters. The block diagram of the PR current control loop is shown in Figure 12. This loop would be the same for each of $\alpha$ and $\beta$ components.

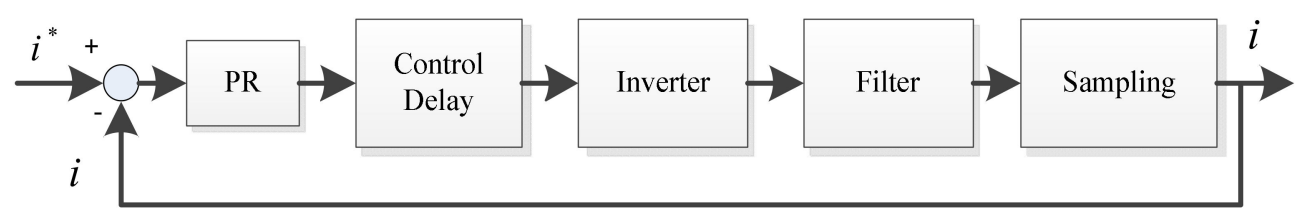

Figure 12. Block diagram of the current control loop.

In this loop, each block is estimated with a transfer function as follows:

$$
\begin{gathered}
G_{\text {Control delay }}=\frac{1}{1+s T_{s}} \\
G_{\text {inverter }}=\frac{1}{1+0.5 s T_{s w}} \\
G_{\text {filter }}=\frac{1}{L s+R} \\
G_{\text {Sampling }}=\frac{1}{1+0.5 s T_{s}}
\end{gathered}
$$

In order to obtain the optimum PR gain values, a discrete pole placement analysis has been utilized by using criteria values in the current control loop $\left(k_{p_{c r t}}=0.34, k_{i c r t}=3.44\right)$. Two requirements have been imposed on the control loop (1) the current loop should be stable, with a phase margin larger than $45^{\circ}$ and a gain margin larger than $6 \mathrm{~dB}$ and (2) the bandwidth of the system should be a minimum of $500 \mathrm{~Hz}$ [37]. 
Considering the transfer function of the PR controller, the $k_{p}$ term is used to adjust the stability of the overall control system. In order to select the $k_{p}$, the root locus method was performed in the discrete-time domain with the Matlab toolbox, Sisotool. As can be seen in Figure 13, the dominant poles had a damping factor of 0.7. Furthermore, it is illustrated that the current control loop with a $k_{p}$ value of 0.3 had a phase margin of $62.8^{\circ}$ and a gain margin of $19.1 \mathrm{~dB}$ and the damping of the resonant poles reached the value of 0.7. Furthermore, it is shown that a stable loop was obtained. An integral gain $k_{i 1}$ of 20 was chosen as a tradeoff between a good noise rejection and good dynamics. In the same way, for cascading PR compensators the integral gains $k_{i 3}, k_{i 5}$, and $k_{i 7}$ of 10,7 , and 5 were chosen, respectively.
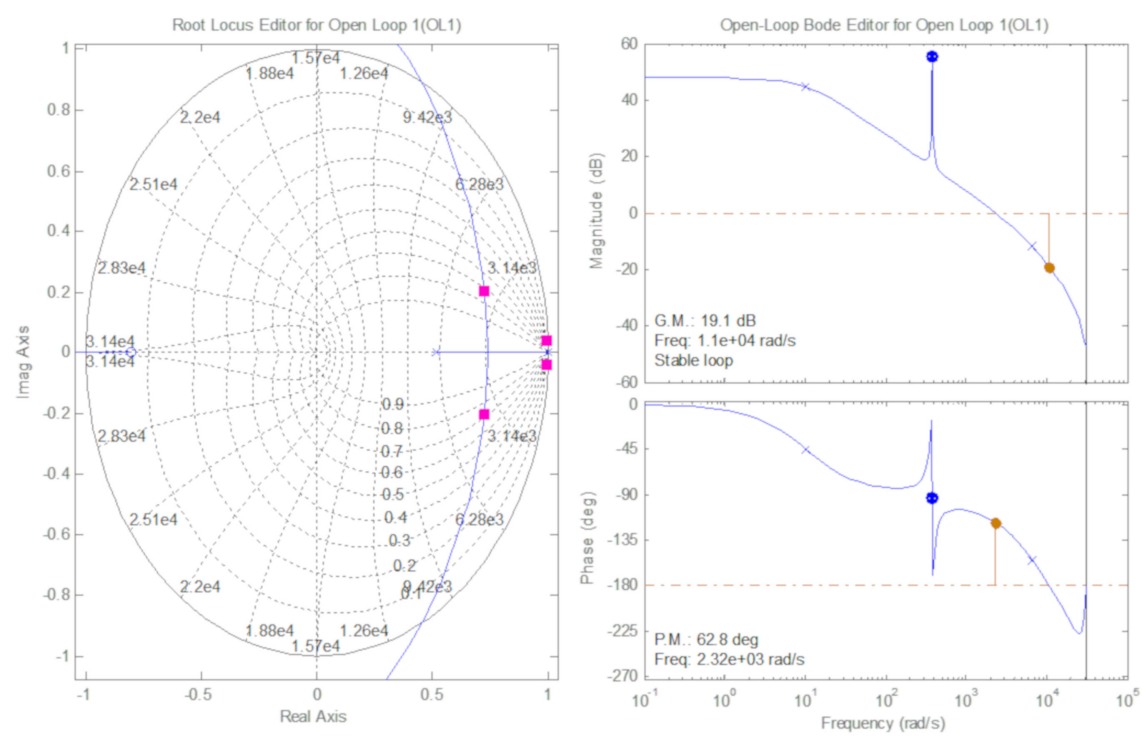

Figure 13. Zero-pole map and the open-loop Bode plot of the PR current control.

Considering the DC voltage loop in Figure 14, the PI controller values are tuned using the optimum symmetrical criterion [38].

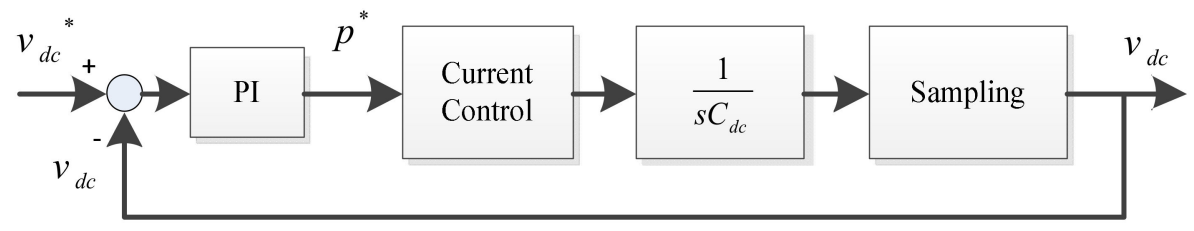

Figure 14. Block diagram of the DC voltage loop.

The block of the current control loop is represented as closed loop transfer function, which can be written as:

$$
G_{i}=\frac{0.5 s T_{s}+1}{2 s T_{\sum 1}+1}
$$

By utilizing the optimum symmetrical method and imposing the phase margin of $45^{\circ}$, the PI parameters can be calculated as:

$$
\begin{aligned}
K_{p} & =0.19 \frac{C_{d c}}{S_{d} T_{s}}=7 \\
K_{i} & =\frac{K_{p}}{3 a^{2} T_{s}}=800
\end{aligned}
$$


where $S_{d}$ is the $d$-component of continuous switching vector via park transformation. Similar to the previous procedure, the $k_{p}$ and $k_{i}$ terms were tuned via the root locus method in the discrete time domain with the Matlab toolbox, Sisotool. Hence, as it is shown in Figure 15 with $k_{p}=7$ and $k_{i}=800 \mathrm{a}$ stable loop a phase margin of $55^{\circ}$ and a gain margin of $25.5 \mathrm{~dB}$ was achieved. Finally, all the controller parameters are displayed in Table 1.
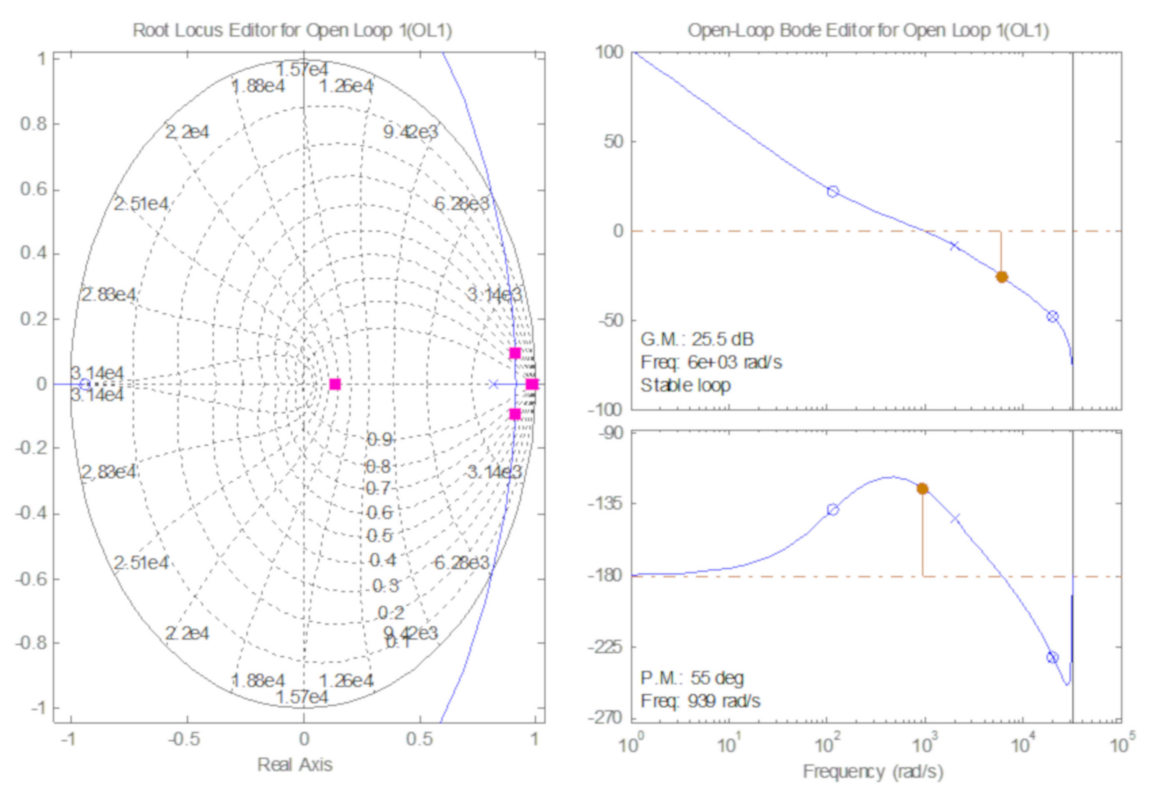

Figure 15. Zero-pole map and the open-loop Bode plot of the voltage control loop.

Table 1. PV system parameters.

\begin{tabular}{ccc}
\hline Symbol & Quantity & Nominal Value \\
\hline $\mathrm{k}$ & QSG gain & $2 \times 0.707$ \\
$\mathrm{k}_{\mathrm{p}, \mathrm{V}}$ & proportional gain of DC-link controller & $7(\mathrm{~A} / \mathrm{V})$ \\
$\mathrm{k}_{\mathrm{i}, \mathrm{V}}$ & integral gain of DC-link controller & $800(\mathrm{~A} / \mathrm{Vs})$ \\
$\mathrm{k}_{\mathrm{p}, \mathrm{PR}}$ & proportional gain of current control & $0.3(\Omega)$ \\
$\mathrm{k}_{\mathrm{i} 1, \mathrm{PR}}$ & integral gain of current control & $20\left(\Omega \mathrm{s}^{2}\right)$ \\
$\mathrm{k}_{\mathrm{i} 3, \mathrm{PR}}$ & integral gain of current control 3th harmonic compensator & $10\left(\Omega \mathrm{s}^{2}\right)$ \\
$\mathrm{k}_{\mathrm{i} 5, \mathrm{PR}}$ & integral gain of current control 5th harmonic compensator & $7\left(\Omega \mathrm{s}^{2}\right)$ \\
$\mathrm{k}_{\mathrm{i} 7, \mathrm{PR}}$ & integral gain of current control 7th harmonic compensator & $5\left(\Omega \mathrm{s}^{2}\right)$ \\
$\xi$ & Damping factor of PR controller & 0.002 \\
\hline
\end{tabular}

\section{Simulation Results}

The simulation results include a comparison between three tests under two types of voltage sag: (1) the conventional current control strategy, (2) the PNSC method performance using the type II PR controller, and (3) the IARC method performance using the type III PR controller. The system is a $100 \mathrm{~kW}$ PV inverter connected to the utility grid by a three-phase three-leg VSC. In addition, the $Y \Delta$ transformer with a three-phase local load after the PV system is interfaced to the grid by a 14-km three-wire transmission line. The PV system parameters are shown in Table 2. The reference for the active and reactive power was assumed to be $100(\mathrm{~kW})$ and zero $(\mathrm{kVAr})$, in all simulations, respectively. Additionally, the LCL filter with a passive damper was designed based on [39]. To ensure the stable operation of the PV system, the minimum value of the DC capacitors was calculated based on [22]. Figures 16 and 17 show the waveform of the grid voltage at PCC. As seen, in $t=0.6 \mathrm{~s}$, a single-phase-to-ground fault ('type B' voltage sag) and a phase-to-phase fault ('type C' voltage sag) occurred [25]. 
Table 2. PV system values.

\begin{tabular}{cc}
\hline Quantity & Nominal Value \\
\hline Maximum output power & $100 \mathrm{~kW}$ \\
Switching frequency & $3 \mathrm{kHz}$ \\
Maximum power PV output voltage & $500 \mathrm{~V}$ \\
DC-link capacitor & $9 \mu \mathrm{F}$ \\
Inverter side inductance & $250 \mu \mathrm{H}$ \\
Inverter side parasitic resistance & $2 \mathrm{~m} \Omega$ \\
Filter capacitor & $45 \mu \mathrm{F}$ \\
Filter damping resistance & $0.6 \Omega$ \\
Grid side inductance & $220 \mu \mathrm{H}$ \\
Grid side parasitic resistance & $2.7 \mathrm{~m} \Omega$ \\
Grid interfaced transformer voltage & $260 \mathrm{~V} / 25 \mathrm{kV}$ \\
Grid frequency & $60 \mathrm{~Hz}$ \\
Sampling frequency & $10 \mathrm{kHz}$ \\
Q reference & $0 \mathrm{VAr}$ \\
\hline
\end{tabular}

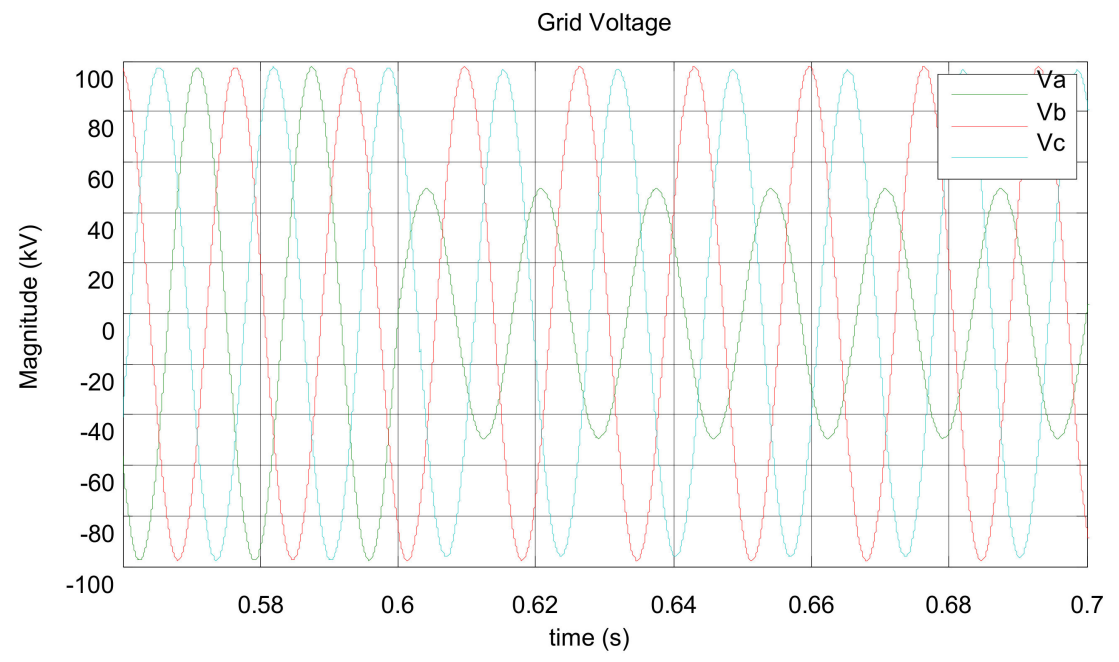

Figure 16. 'type B' voltage sag.

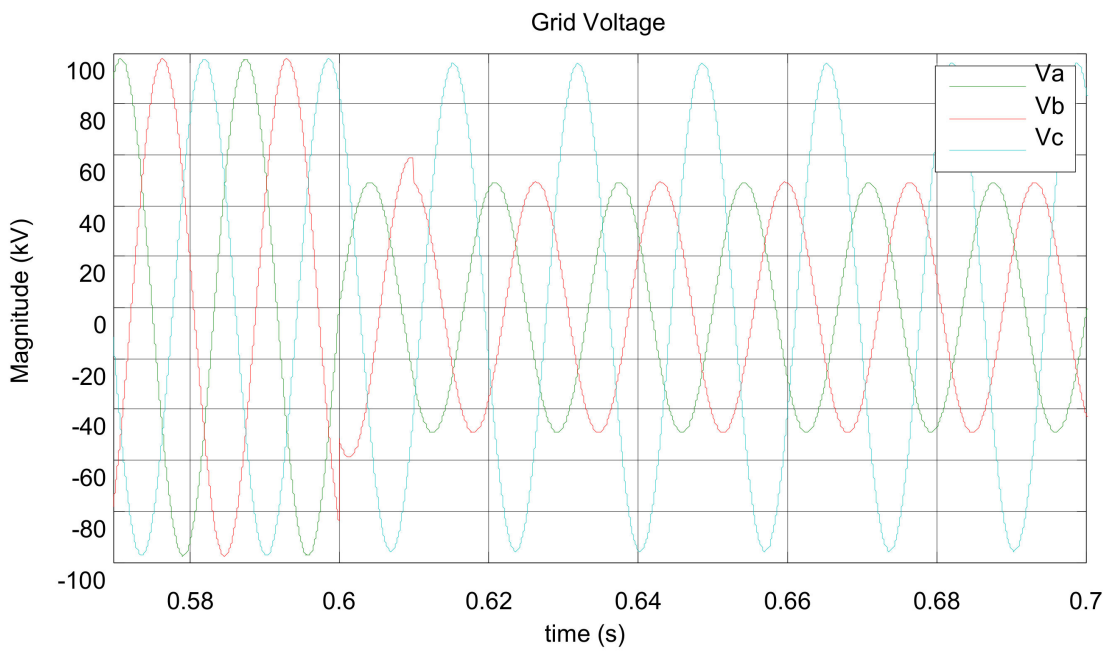

Figure 17. 'type C' voltage sag.

In the following sections, two grid cycles are given to the FLL synchronize with the grid voltage. After a transient period of $t=0.1 \mathrm{~s}$, the first dynamic response of the proposed method in comparison 
with the conventional method is shown. In $t=0.25 \mathrm{~s}$, the MPPT algorithm is triggered that makes the active power to be increased to $5 \mathrm{~kW}$, without any impact on the reactive power.

\subsection{Conventional Current Control Method}

To clarify the quality of reference currents, three generating methods were used in this paper. First, the conventional method was simulated [23]. Figure 18 shows the performance of the conventional method, which produced intensive oscillations in the active and reactive power. The DC-link voltage with the conventional current control method is also presented in Figure 19. As can be observed, the DC-link voltage was not constant and oscillations with considerable amplitude appeared during the voltage sag.

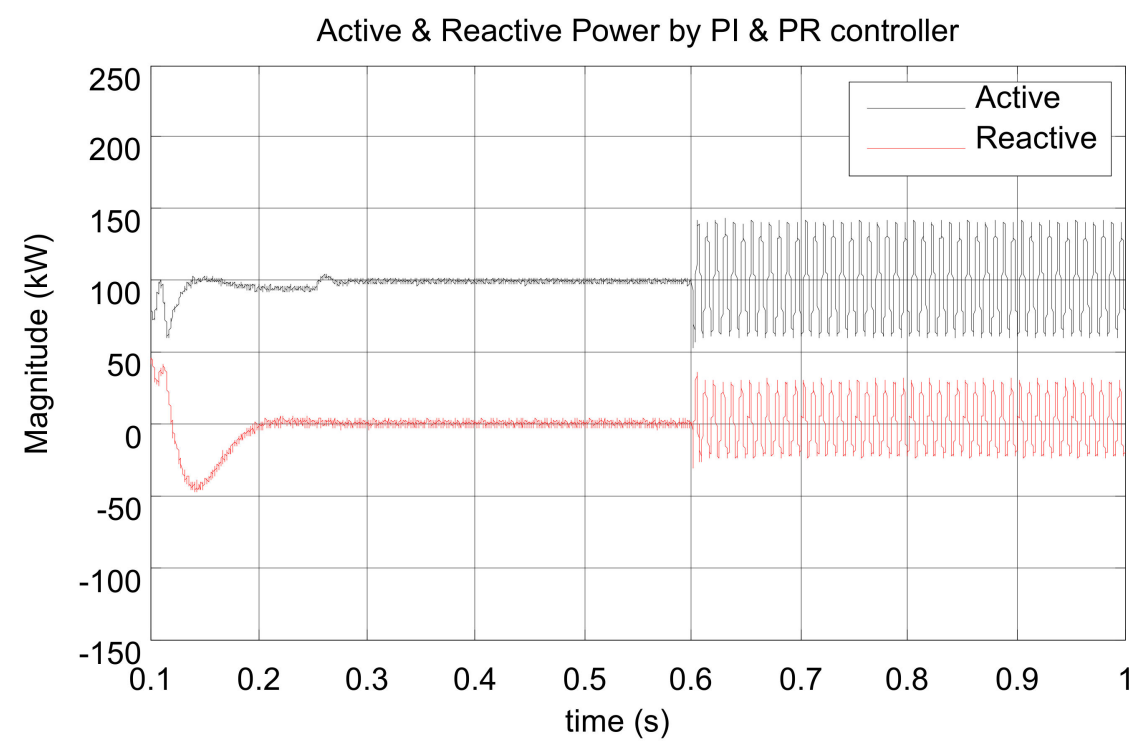

Figure 18. Injected instantaneous power into the grid via the conventional method.

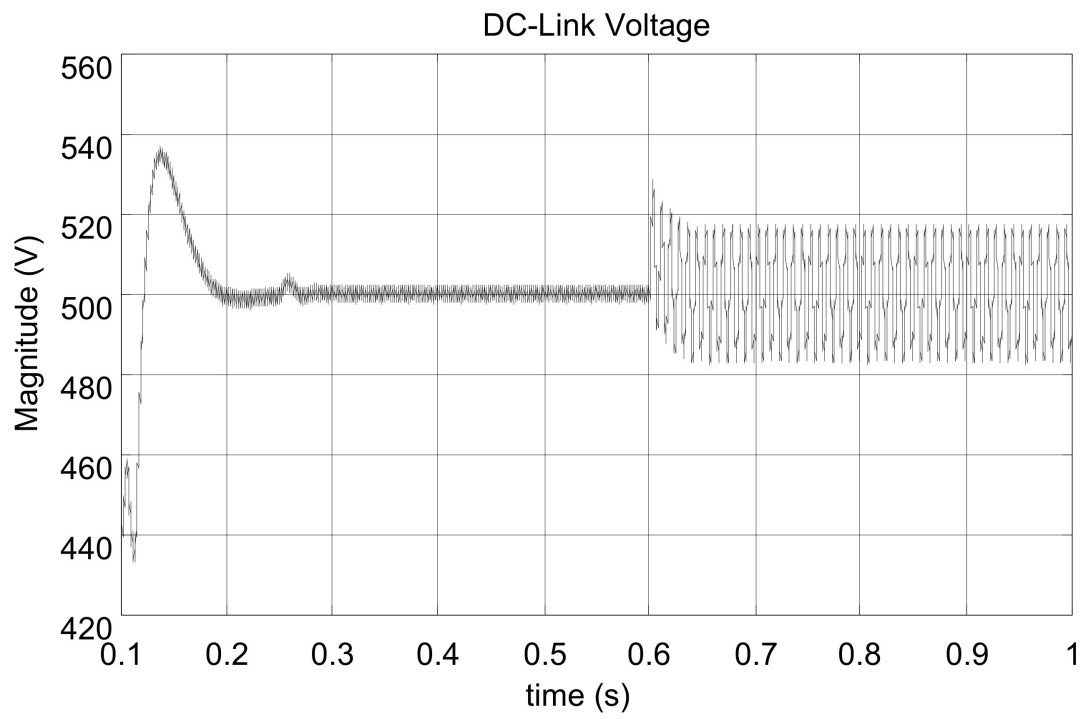

Figure 19. DC-link capacitor voltage via the conventional method. 


\subsection{PNSC Method Performance Using the Type II PR Controller}

The output power under 'type B' and 'type C' voltage sag by using the PNSC method is depicted in Figures 20 and 21, which shows the effective performance of the proposed method in canceling out active power oscillations completely. Moreover, the comparison of the performance between the PNSC method and the conventional method indicates the higher quality of the PNSC power adjustment. The DC-link capacitors' voltage under 'type B' and 'type $C^{\prime}$ faults are shown in Figures 22 and 23. It shows the response of implementing the PNSC, which indicates $55.5 \%$ and $45 \%$ reduction in the amplitude of voltage oscillations when compared with the conventional method, respectively.

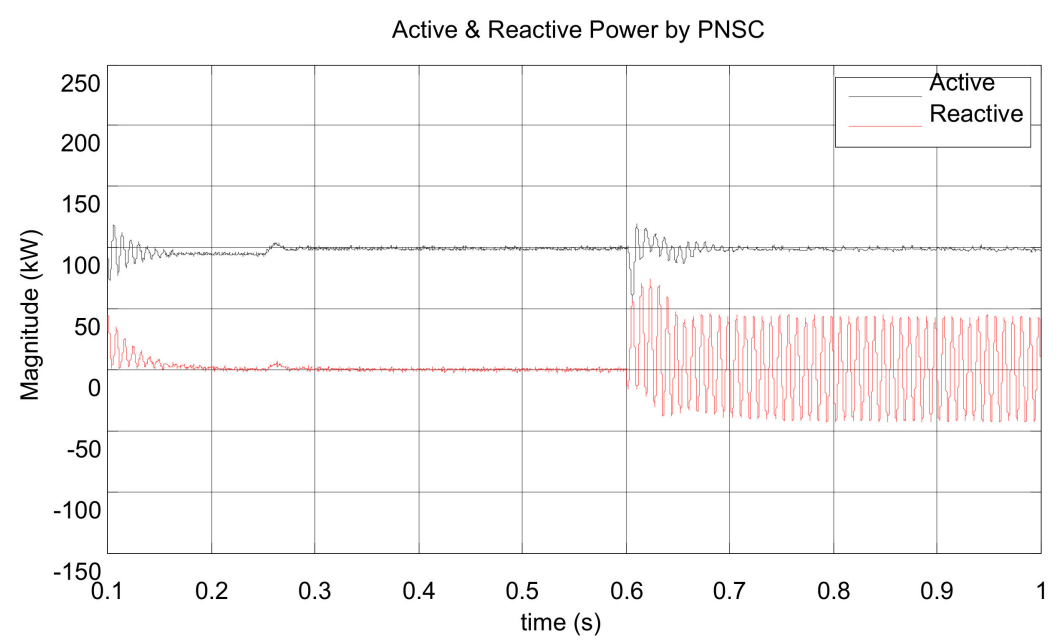

Figure 20. Injected instantaneous power into the grid under 'type B' voltage sag.

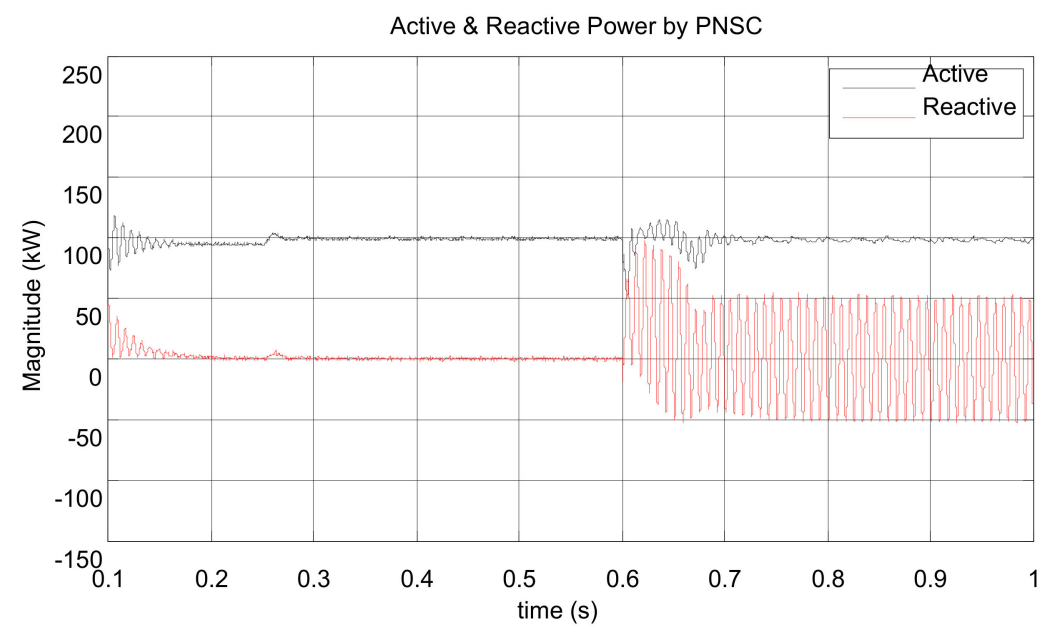

Figure 21. Injected instantaneous power into the grid under 'type $C^{\prime}$ voltage sag. 


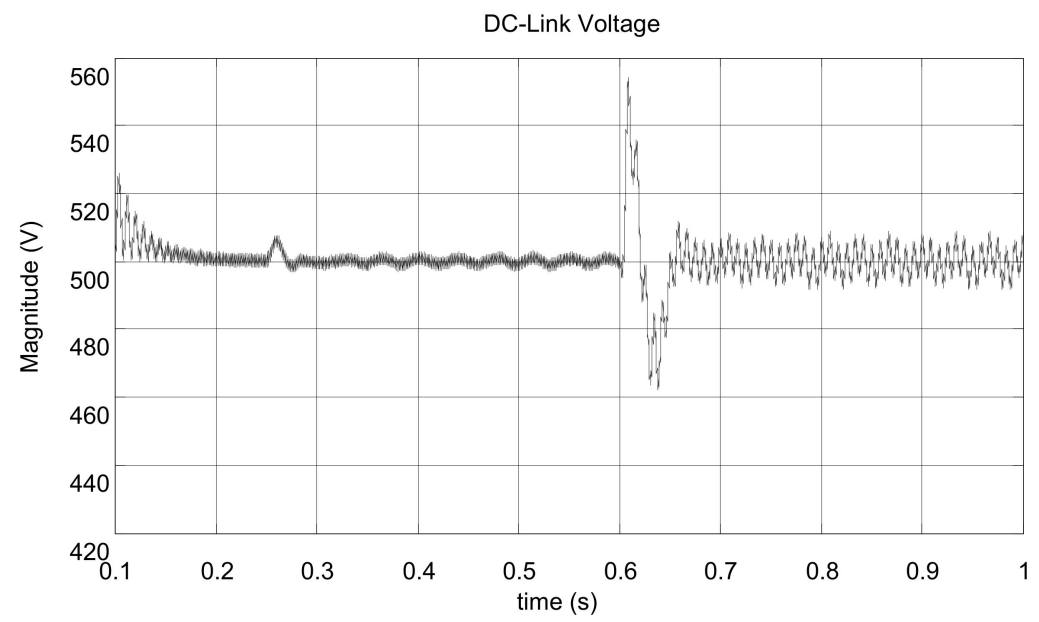

Figure 22. DC-link capacitor voltage under 'type B' voltage sag.

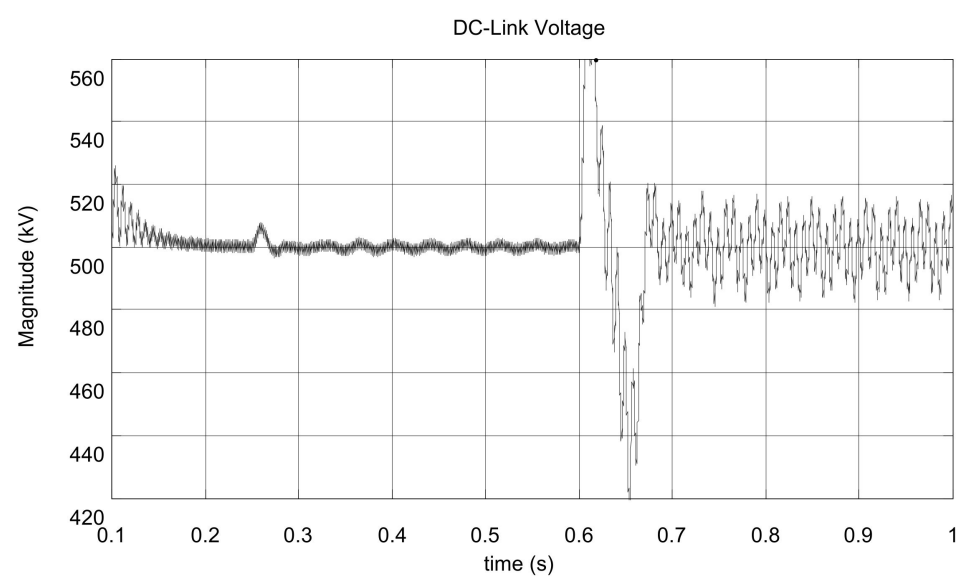

Figure 23. DC-link capacitor voltage under 'type $C^{\prime}$ voltage sag.

The proper three-phase unbalanced reference currents generated by the PNSC method before and after fault occurrence is shown in Figure 24, which indicate the appropriate performance of the PNSC method and accurate current tracking by the controller. 

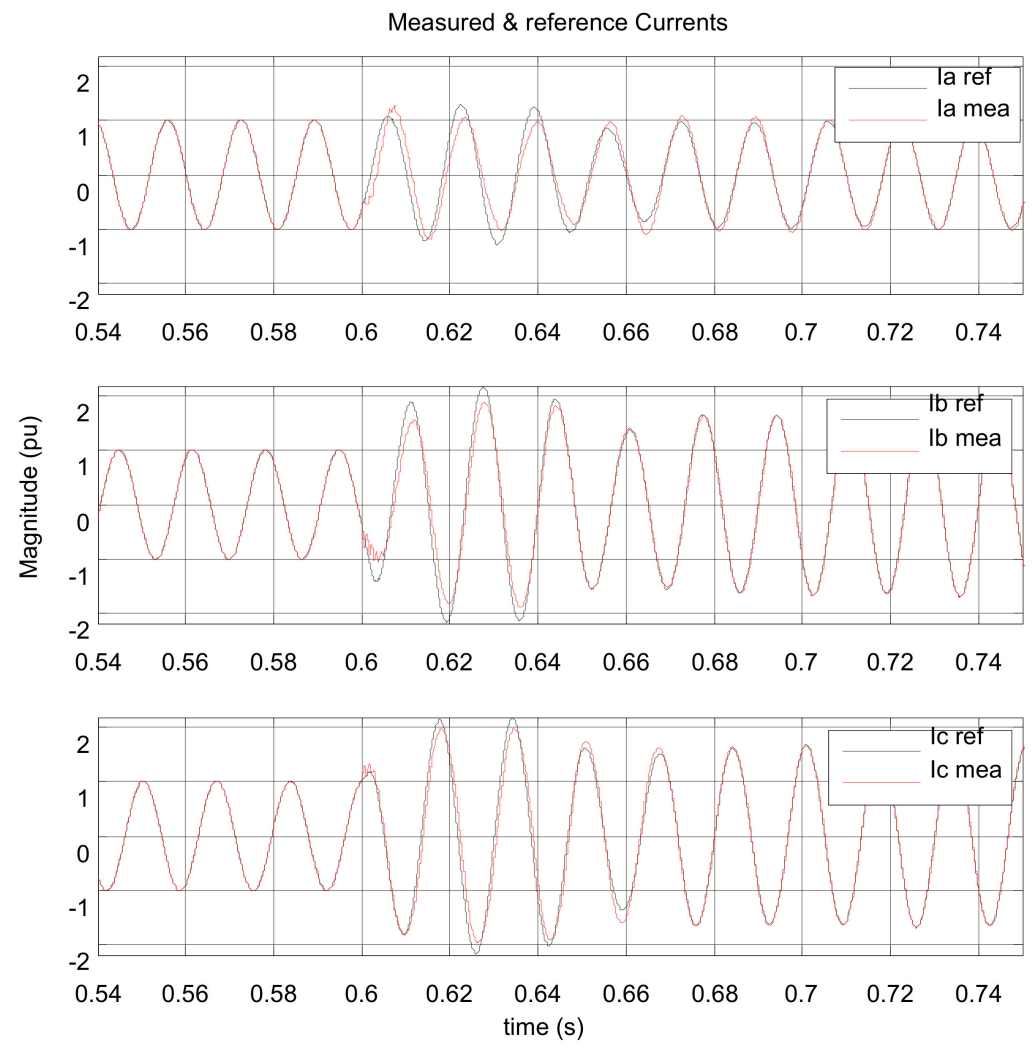

Figure 24. Current reference generated with the PNSC and grid current measured.

\subsection{IARC Method Performance Using the Type III PR Controller}

The performance of the IARC, along with the non-ideal current control loop with harmonic compensators was simulated and the results are illustrated in Figures 25 and 26. The current control loop responses until $t=0.2 \mathrm{~s}$ clearly demonstrated the fast transient dynamic response. After $t=0.6 \mathrm{~s}$ with occurring faults, it indicates a significant decrease in the active and reactive power oscillations, instantaneously. This fact verified the proper response of the control loop using the IARC method under two types of common faults, in comparison to the conventional and PNSC method.

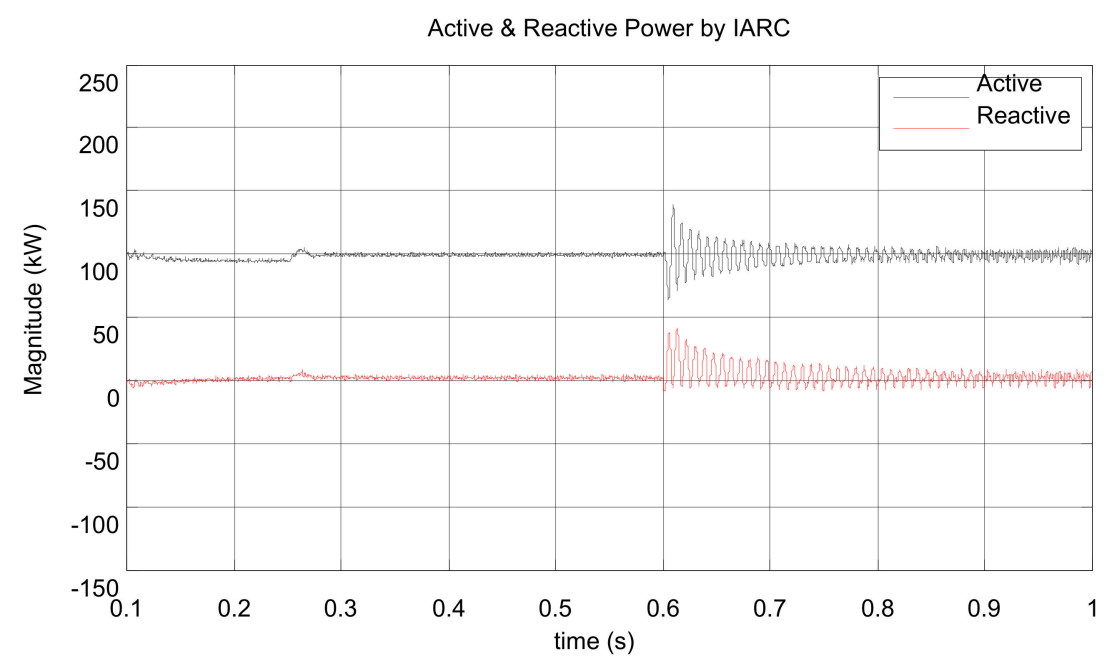

Figure 25. Injected instantaneous power into the grid under 'type B' voltage sag. 


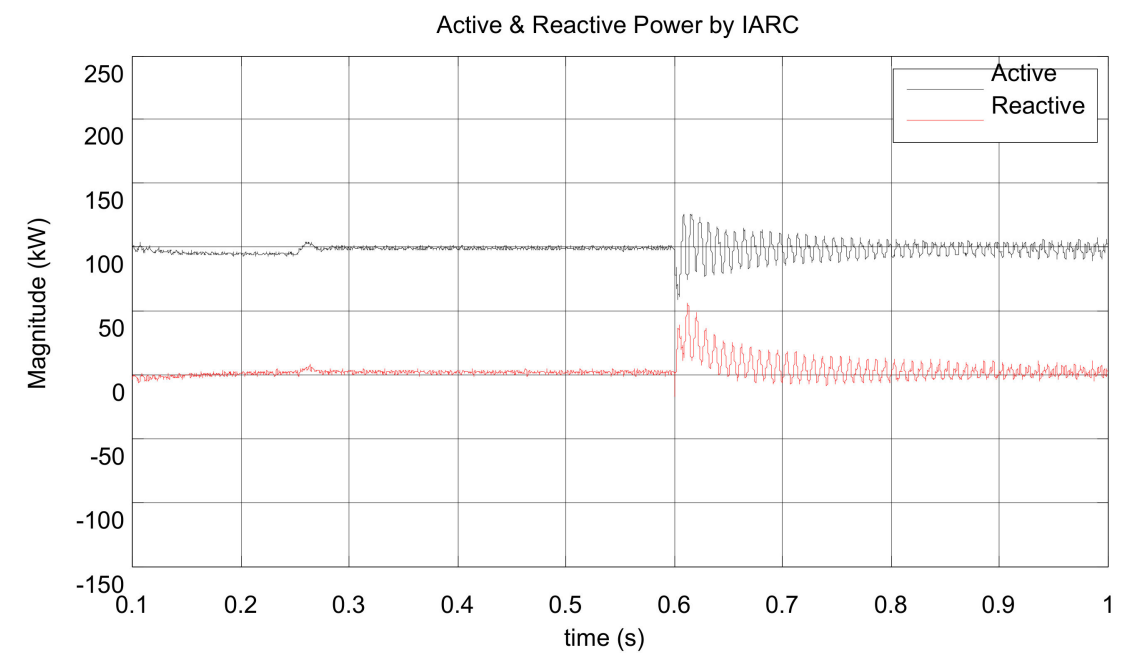

Figure 26. Injected instantaneous power into the grid under 'type $C^{\prime}$ voltage sag.

Figures 27 and 28 show the DC-link voltage of the capacitor when the IARC method was implemented. The IARC method shows around a 50\% reduction in the amplitude of voltage oscillations. The three-phase reference currents generated by the IARC method and injected currents via the non-ideal PR controller with harmonic compensators are shown in Figure 29. It indicates that, after the fault period, the harmonic reference currents generated were tracked properly.

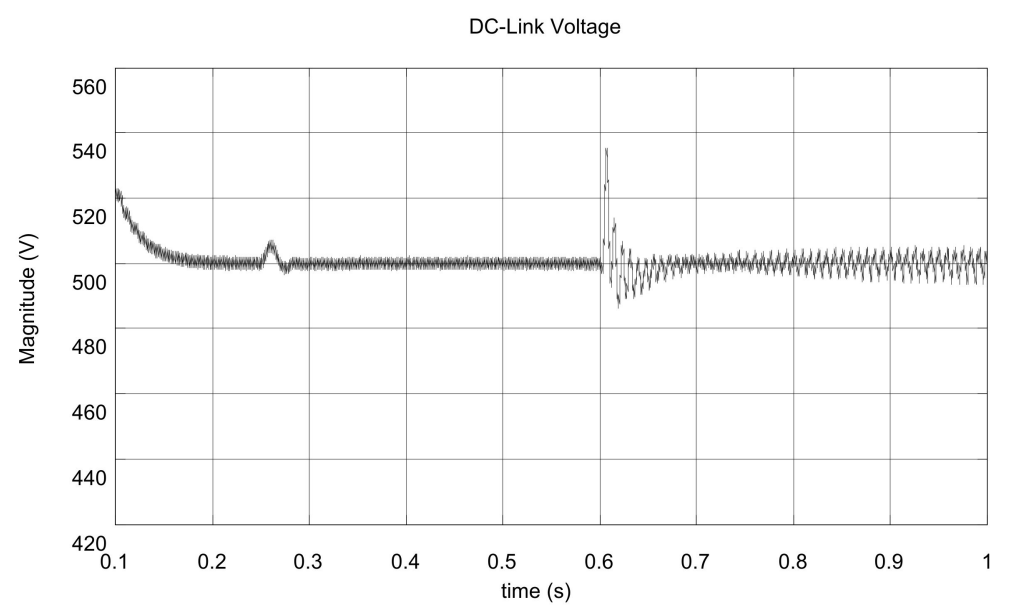

Figure 27. DC-link capacitor voltage under 'type B' voltage sag. 


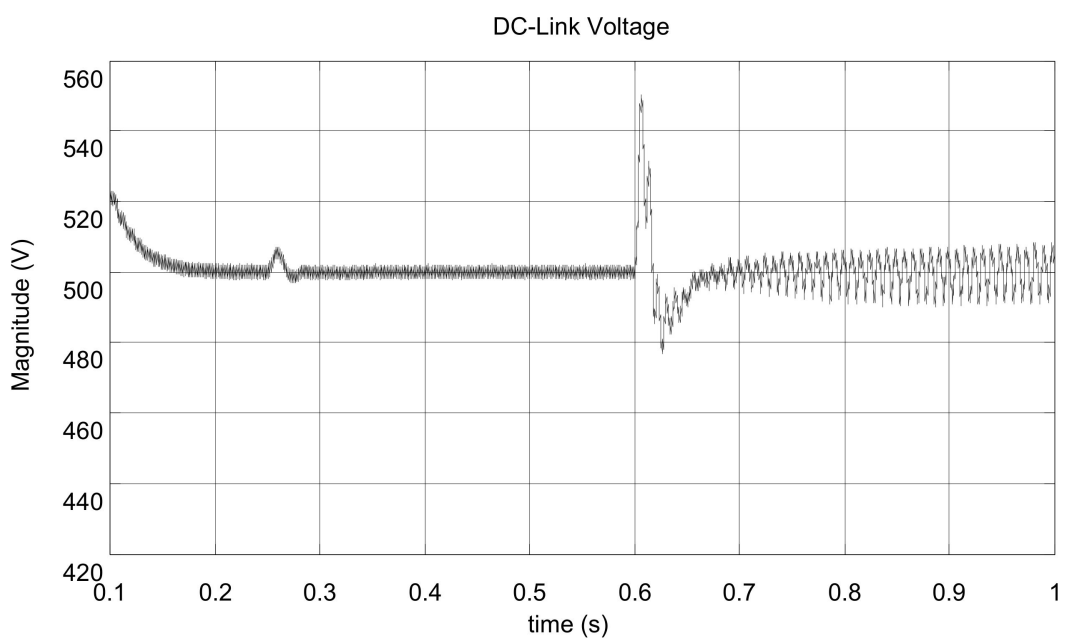

Figure 28. DC-link capacitor voltage under 'type C' voltage sag.
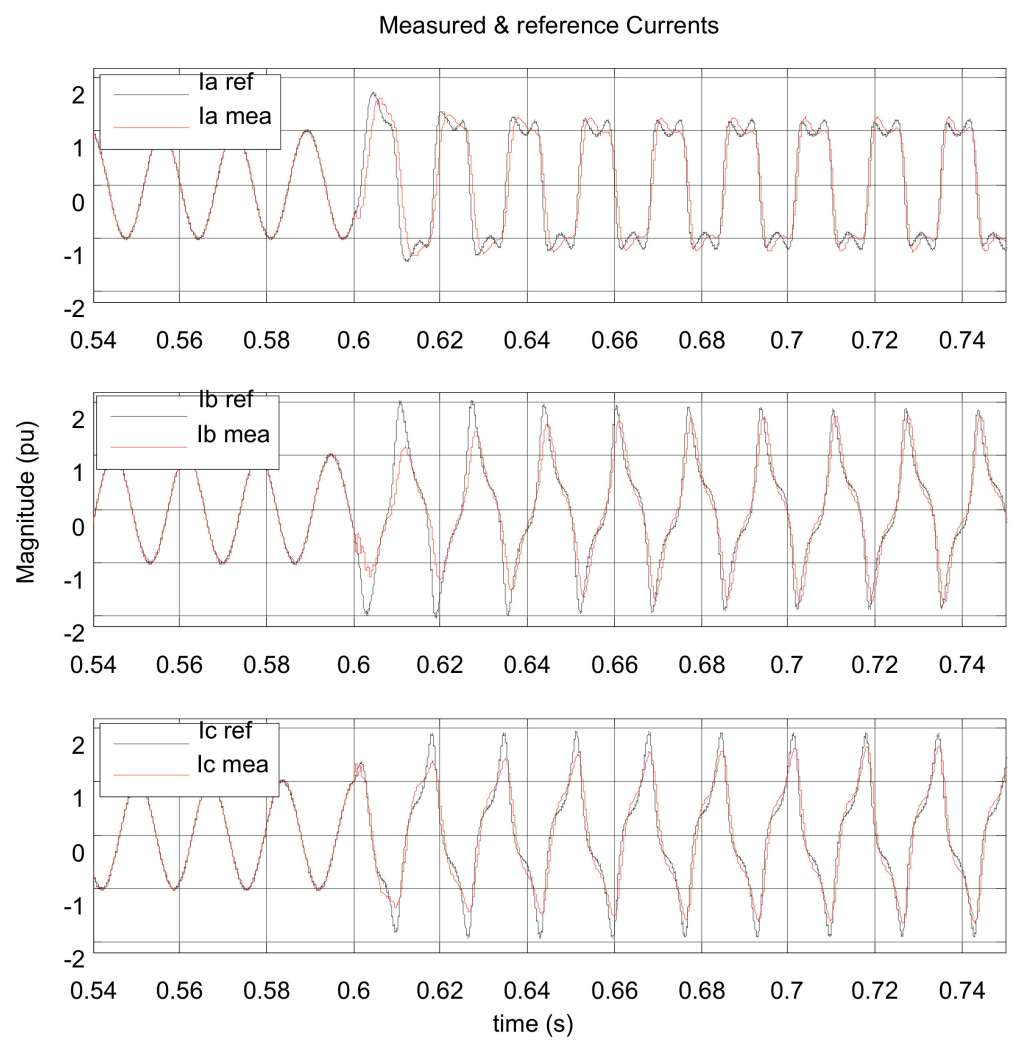

Figure 29. Current reference generated with IARC and grid current measured.

Moreover, the Fast Fourier Transform (FFT) analysis for one phase of injected currents via the IARC method is shown in Figure 30. It is contained with high total harmonic distortion (THD) as $21.11 \%$ of the fundamental frequency. The harmonic orders as a percentage of the fundamental frequency are shown in Table 3. 


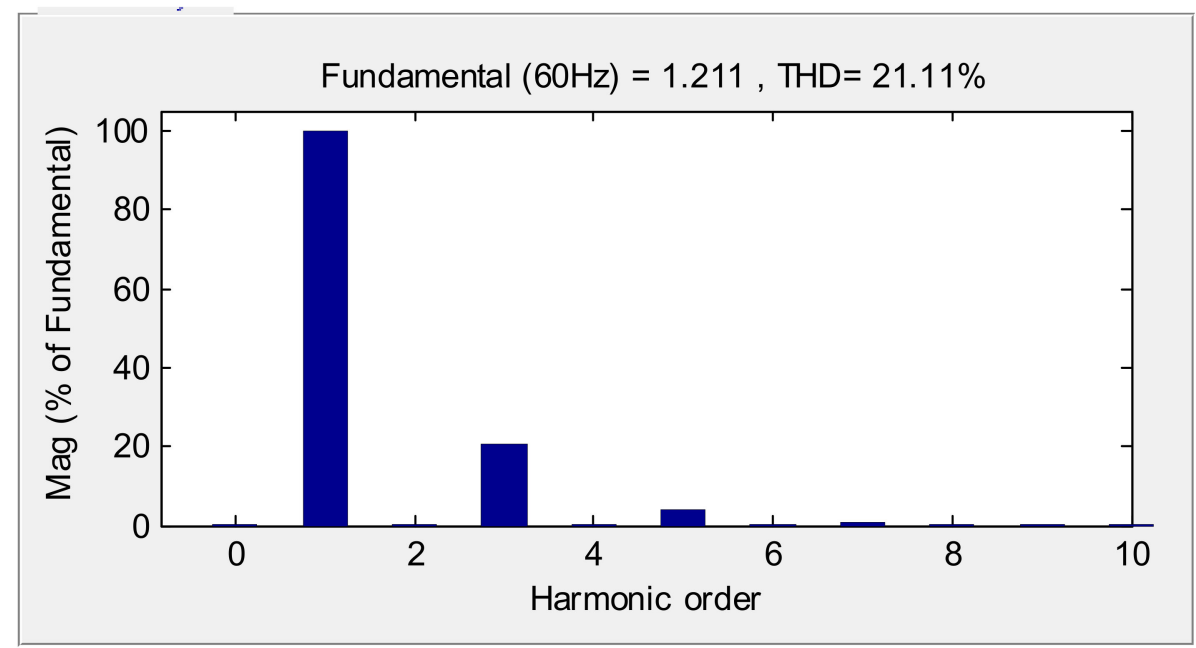

Figure 30. FFT analysis diagram for injected current via the IARC method.

Table 3. Current signals harmonics.

\begin{tabular}{cc}
\hline Harmonic Orders & Values Based on a Percentage of the Fundamental Frequency \\
\hline 3 th & $21 \%$ \\
5 th & $5.5 \%$ \\
7 th & $1 \%$ \\
9 th & $0.25 \%$ \\
\hline
\end{tabular}

\section{Conclusions}

This paper suggested an improved control scheme for a three-phase two-stage PV converter by the combination of the FLL and PR current reference generator to improve the power quality under abnormal conditions. The proposed method has the ability to mitigate the double grid frequency oscillations in the DC-link voltage and the active and reactive powers under unbalanced faults. Ananalytical method was used to obtain the optimum value of controllers' parameters. To generate the appropriate reference current, two methods, including PNSC with type II of the PR controller and IARC with type III of the PR controller were applied. The simulation results illustrated that the IARC method along with type III of PR controller effectively mitigates the double grid frequency oscillations in the DC-link voltage, active power, and active power under unbalanced grid faults.

Author Contributions: All authors participated equally in conceptualization, methodology, implementation, and writing-review and editing the paper. Additionally, all authors have read and agreed to the published version of the manuscript.

Funding: This research received no external funding.

Conflicts of Interest: The authors declare no conflict of interest.

\section{Abbreviations}

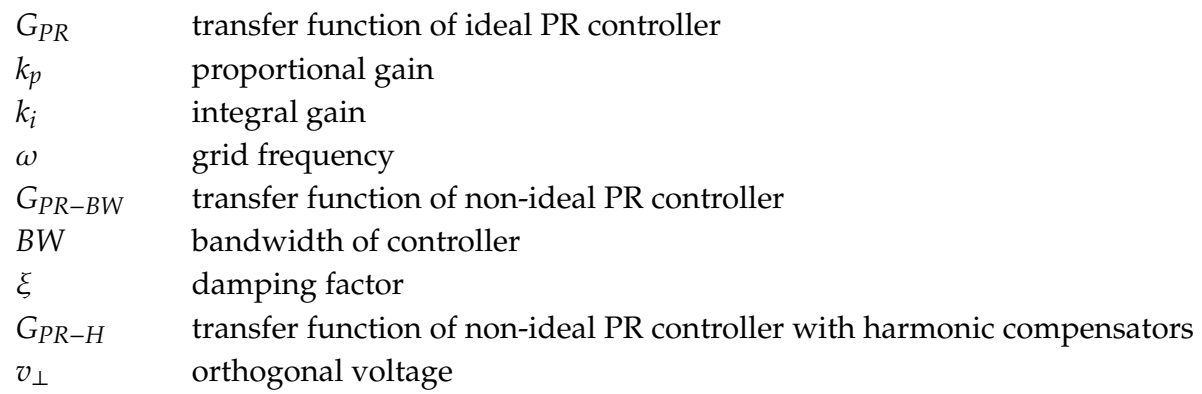




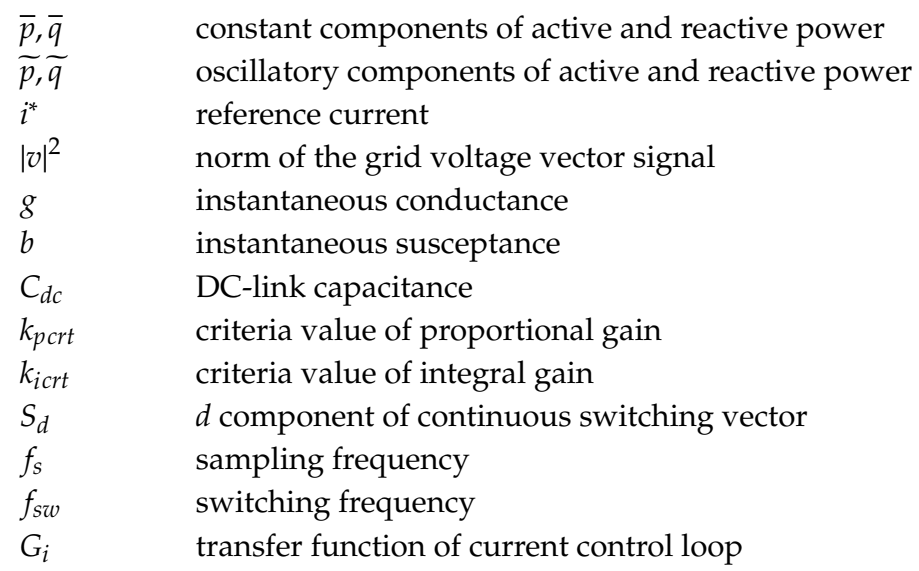

\section{References}

1. Miveh, M.R.; Mohd, F.G.; Ali, M.M. Control techniques for three-phase four-leg voltage source inverters in autonomous microgrids: A review. Renew. Sustain. Energy Rev. 2016, 54, 1592-1610. [CrossRef]

2. Shojaei, A.H.; Ghadimi, A.A.; Miveh, M.R.; Mohammadi, F.; Jurado, F. Multi-Objective Optimal Reactive Power Planning under Load Demand and Wind Power Generation Uncertainties Using $\varepsilon$-Constraint Method. Appl. Sci. 2020, 10, 2859. [CrossRef]

3. Ghadimi, A.A.; Daryani, A.M.; Rastegar, H. Detailed Modeling and analysis of a full bridge PWM DC-DC converter. In Proceedings of the Australasian Universities Power Engineering Conference (AUPEC06), Melbourne, Sydney, Australia, 10-13 December 2006.

4. Jenniches, S.; Worrell, E. Regional economic and environmental impacts of renewable energy developments: Solar PV in the Aachen Region. Energy Sustain. Dev. 2019, 48, 11-24. [CrossRef]

5. Mahdavi, M.S.; Gharehpetian, G.B.; Ranjbaran, P.; Azizi, H. Frequency Regulation of AUT Microgrid Using Modified Fuzzy PI Controller for Flywheel Energy Storage System. AUT J. Electr. Eng. 2018, 51, 31-38.

6. Yilmaz, U.; Kircay, A.; Borekci, S. PV system fuzzy logic MPPT method and PI control as a charge controller. Renew. Sustain. Energy Rev. 2018, 81, 994-1001. [CrossRef]

7. Tafti, H.D.; Maswood, A.I.; Lim, Z.; Gabriel, O.; Pinkymol, H. A review of active/reactive power control strategies for PV power plants under unbalanced grid faults. In Proceedings of the Innovative Smart Grid Technologies-Asia (ISGT ASIA), Bangkok, Thailand, 4-6 November 2015.

8. Miveh, M.R.; Mohd, F.G.; Ali, M.M. Power quality improvement in autonomous microgrids using multi-functional voltage source inverters: A comprehensive review. J. Power Electron. 2015, 15, 1054-1065. [CrossRef]

9. Rezvani, A.; Gandomkar, M. Modeling and control of grid connected intelligent hybrid photovoltaic system using new hybrid fuzzy-neural method. Sol. Energy 2016, 127, 1-18. [CrossRef]

10. Yang, Y.; Blaabjerg, F.; Wang, H. Low-voltage ride-through of single-phase transformerless photovoltaic inverters. IEEE Trans. Ind. Appl. 2014, 50, 1942-1952. [CrossRef]

11. Afshari, E.; Moradi, G.R.; Yang, Y.; Farhangi, B.; Farhangi, S. A review on current reference calculation of three-phase grid-connected PV converters under grid faults. In Proceedings of the Power and Energy Conference at Illinois (PECI), Champaign, IL, USA, 23-24 February 2017.

12. Mirhosseini, M.; Pou, J.; Karanayil, B.; Agelidis, V.G. Positive and negative-sequence control of grid-connected photovoltaic systems under unbalanced voltage conditions. In Proceedings of the Power Engineering Conference (AUPEC), Australasian Universities, Hobart, Australia, 29 September-3 October 2013.

13. Castilla, M.; Miret, J.; Camacho, A.; Matas, J.; de Vicuña, L.G. Reduction of Current Harmonic Distortion in Three-Phase Grid-Connected Photovoltaic Inverters via Resonant Current Control. IEEE Trans. Ind. Electron. 2013, 60, 1464-1472. [CrossRef]

14. Dash, A.R.; Babu, B.C.; Mohanty, K.B.; Dubey, R. Analysis of PI and PR Controllers for Distributed Power Generation System under Unbalanced Grid Faults. In Proceedings of the International Conference on Power and Energy Systems (ICPS), Chennai, India „, 22-24 December 2011. 
15. Vidal, A.; Freijedo, F.D.; Yepes, A.G.; Fernandez-Comesana, P.; Malvar, J.; López, Ó.; Doval-Gandoy, J. Assessment and Optimization of the Transient Response of Proportional-Resonant Current Controllers for Distributed Power Generation Systems. IEEE Trans. Ind. Electron. 2013, 60, 1367-1383. [CrossRef]

16. Teodorescu, R.; Blaabjerg, F.; Liserre, M.; Loh, P.C. Loh Proportional-Resonant Controllers and Filters for Grid-Connected Voltage-Source Converters. IEE Proc. Electr. Power Appl. 2006, 153, 750-762. [CrossRef]

17. Jiabing, H.; Yikang, H. Modeling and Control of Grid-Connected Voltage-Sourced Converters Under Generalized Unbalanced Operation Conditions. IEEE Trans. Energy Convers. 2008, 23, 903-913. [CrossRef]

18. Teodorescu, R.; Marco, L.; Pedro, R. Grid Converters for Photovoltaic and Wind Power Systems; John Wiley \& Sons: Hoboken, NJ, USA, 2011.

19. Shao, Z.; Xing, Z.; Fusheng, W.; Renxian, C.; Hua, W. Analysis and control of neutral-point voltage for transformerless three-level PV inverter in LVRT operation. EEE Trans. Power Electron. 2017, 32, 2347-2359. [CrossRef]

20. Wang, Z.; Bin, W.; Dewei, X.; Ming, C.; Liang, X. Dc-link current ripple mitigation for current-source grid-connected converters under unbalanced grid conditions. IEEE Trans. Ind. Electron. 2016, 63, 4967-4977. [CrossRef]

21. Guo, X.; Liu, W.; Lu, Z. Flexible power regulation and current-limited control of the grid-connected inverter under unbalanced grid voltage faults. IEEE Trans. Ind. Electron. 2017, 64, 7425-7432. [CrossRef]

22. Messo, T.; Jokipii, J.; Puukko, J.; Suntio, T. Determining the Value of DC-Link Capacitance to Ensure Stable Operation of a Three-Phase Photovoltaic Inverter. IEEE Trans. Power Electron. 2014, 29, 665-673. [CrossRef]

23. Yazdani, A.; Dash, P.P. A Control Methodology and Characterization of Dynamics for a Photovoltaic (PV) System Interfaced With a Distribution Network. IEEE Trans. Power Deliv. 2009, 24, 1538-1551. [CrossRef]

24. Figueres, E.; Garcerá, G.; Sandia, J.; Gonzalez-Espin, F.; Rubio, J.C. Sensitivity Study of the Dynamics of Three-Phase Photovoltaic Inverters With an LCL Grid Filter. IEEE Trans. Ind. Electron. 2009, 56, 706-717. [CrossRef]

25. Taul, M.G.; Wang, X.; Davari, P.; Blaabjerg, F. An overview of assessment methods for synchronization stability of grid-connected converters under severe symmetrical grid faults. IEEE Trans. Power Electron. 2019, 34, 9655-9670. [CrossRef]

26. Rodriguez, P.; Luna, A.; Candela, I.; Teodorescu, R.; Blaabjerg, F. Grid synchronization of power converters using multiple second order generalized integrators. In Proceedings of the 34th Annual Conference of IEEE, Orlando, FL, USA, 10-13 November 2008.

27. Rodriguez, P.; Luna, A.; Etxeberría, I.; Hermoso, J.R.; Teodorescu, R. Multiple Second Order Generalized Integrators for Harmonic Synchronization of Power Converters. In Proceedings of the 2009 Energy Conversion Congress and Exposition ECCE, IEEE, San Jose, CA, USA, 20-24 September 2009.

28. Wang, Z.; Fan, S.; Zou, Z.; Zheng, Y.; Cheng, M. Operation of interleaved voltage-source-converter fed wind energy systems with asymmetrical faults in grid. In Proceedings of the 7th International Power Electronics and Motion Control Conference (IPEMC), Harbin, China, 2-5 June 2012.

29. Camacho, A.; Castilla, M.; Miret, J.; Vasquez, J.C.; Alarcón-Gallo, E. Flexible Voltage Support Control for Three-Phase Distributed Generation Inverters Under Grid Fault. IEEE Trans. Ind. Electron. 2013, 60, 1429-1441. [CrossRef]

30. Rodriguez, P.; Luna, A.; Ciobotaru, M.; Teodorescu, R.; Blaabjerg, F. Advanced Grid Synchronization System for Power Converters under Unbalanced and Distorted Operating Conditions. In Proceedings of the 32nd Annual Conference on IEEE Industrial Electronics, Paris, France, 7-10 November 2006.

31. Enslin, J.H.R. Maximum power point tracking: A cost saving necessity in solar energy systems. In Proceedings of the 16th Annual Conference of IEEE Industrial Electronics Society, California, CA, USA, 27-30 November 1990.

32. Esram, T.; Chapman, P.L. Comparison of Photovoltaic Array Maximum Power Point Tr acking Techniques. IEEE Trans. Energy Convers. 2007, 22, 439-449. [CrossRef]

33. De Brito, M.A.G.; Galotto, L.; Sampaio, L.P.; e Melo, G.D.A.; Canesin, C.A. Evaluation of the Main MPPT Techniques for Photovoltaic Applications. IEEE Trans. Ind. Electron. 2013, 60, 1156-1167. [CrossRef]

34. Zmood, D.N.; Holmes, D.G. Stationary frame current regulation of PWM inverters with zero steady state error. In Proceedings of the 30th Annual IEEE Power Electronics Specialists Conference, Charleston, SC, USA, 1 July 1999. 
35. Cha, H.; Vu, T.K.; Kim, J.E. Design and control of Proportional-Resonant controller based Photovoltaic power conditioning system. In Proceedings of the Energy Conversion Congress and Exposition, California, CA, USA, 20-24 September 2009.

36. Monfared, M.; Golestan, S. Control strategies for single-phase grid integration of small-scale renewable energy sources: A review. Renew. Sustain. Energy Rev. 2012, 16, 4982-4993. [CrossRef]

37. Julean, A.M. Active Damping of LCL Filter Resonance in Grid Connected Applications. Master's Thesis, Aalborg University, Aalborg, Denmark, 2009.

38. Liserre, M.; Dell'Aquila, A.; Blaabjerg, F. Design and control of a three-phase active rectifier under non-ideal operating conditions. In Proceedings of the 37th IAS Annual Meeting Industry Applications Conference, Pittsburgh, PA, USA, 13-18 October 2002.

39. Liserre, M.; Blaabjerg, F.; Hansen, S. Design and control of an LCL-filter-based three-phase active rectifier. IEEE Trans. Ind. Appl. 2005, 41, 1281-1291. [CrossRef]

(C) 2020 by the authors. Licensee MDPI, Basel, Switzerland. This article is an open access article distributed under the terms and conditions of the Creative Commons Attribution (CC BY) license (http://creativecommons.org/licenses/by/4.0/). 